\title{
A AVALIAÇÃO DA PÓS-GRADUAÇÃO STRICTO SENSU NO CONTEXTO DOS INSTITUTOS FEDERAIS DE EDUCAÇÃO, CIÊNCIA E TECNOLOGIA
}

\section{A EVALUATION OF POST-GRADUATE STRICTO SENSU COURSES IN THE CONTEXT OF FEDERAL INSTITUTES OF EDUCATION, SCIENCE AND TECHNOLOGY}

\section{Carina Gomes Messias Alves, José Claudio Del Pino}

Universidade Federal do Rio Grande do Sul

E-mail: carina.messias@capes.gov.br, delpinojc@yahoo.com.br

\section{Resumo}

Os Institutos Federais de Educação, Ciência e Tecnologia - IFs foram criados pela Lei no 11.892/2008 a partir da agregação/transformação de antigas instituições de educação profissional. Antes da denominação como Instituto Federal, essas instituições já atuavam no Sistema Nacional de Pós-Graduação - SNPG buscando ofertar cursos de Pós-Graduação stricto sensu. Em 2000, foi submetida a primeira proposta de curso e, em 2004, foi recomendado pela CAPES o primeiro curso de Pós-Graduação ofertado por IF. Tendo em vista o contexto de submissão de proposta de curso novo, recomendação e reavaliação de curso de pós-graduação stricto sensu pela CAPES, o objetivo do presente estudo é analisar a participação e o desempenho dos IFs no SNPG.

Palavras-chave: educação profissional. Institutos Federais de Educação, Ciência e Tecnologia. Sistema Nacional de Pós-Graduação. avaliação da pós-graduação.

\begin{abstract}
The Federal Institutes of Education, Science and Technology - IFs were created by Law $\mathrm{N}^{\circ}$. $11.892 / 2008$, from the aggregation/transformation of old professional education insitutions. Before their designation as Federal Institutes, these institutions had already worked in the National Post-Graduation System (SNPG), seeking to offer stricto sensu post-graduate courses. In 2000, the first course proposal was submitted and, in 2004, the first postgraduate course offered by a Federal Institute was recommended by CAPES. Considering the context of submission, recommendation and reassessment of new post-graduate stricto sensu course proposals, by CAPES, the objective of this study is to analyze the participation and performance of IFs in SNPG.
\end{abstract}

Palavras-chave: professional education. Federal Institutes of Education, Science and Technology. National Post-Graduation System. graduate evaluation. 


\section{INTRODUÇÃO}

O artigo em tela apresenta uma análise sobre a participação e desempenho dos Institutos Federais de Educação, Ciência e Tecnologia - IFs no contexto do Sistema Nacional de Avaliação da Pós-Graduação - SNPG implantado pela Coordenação de Aperfeiçoamento de Pessoal de Nível Superior - CAPES.

Os IFs são instituições de educação superior, básica e profissional, pluricurriculares e multicampi, especializados na oferta de educação profissional e tecnológica nas diferentes modalidades de ensino, com base na conjugação de conhecimentos técnicos e tecnológicos com as suas práticas pedagógicas (BRASIL, 2008).

A criação dos IFs se deu por meio da Lei 11.892, de 29 de dezembro de 2008, que instituiu a Rede Federal de Educação Profissional, Científica e Tecnológica e criou os 38 Institutos Federais de Educação, Ciência e Tecnologia oriundos dos Centros Federais de Educação Tecnológica - CEFETs, Unidades de Ensino Descentralizadas - UNEDs, Escolas Agrotécnicas, Escola Técnica Federal - ETF e Escolas Vinculadas às Universidades Federais.

Nos incisos do art. 60 da Lei no 11.892/08, que tratam das finalidades e características dos IFs, fica evidente a preocupação com uma proposta de instituição que ofereça educação profissional e tecnológica em todos os níveis e modalidades de ensino, incluindo a oferta de cursos de pós-graduação stricto sensu.

Dentre os objetivos dos Institutos, previstos no art. 7ạ da referida lei, também trata sobre ministrar em nível de educação superior cursos de pós-graduação stricto sensu de mestrado e doutorado, que contribuam para promover o estabelecimento de bases sólidas em educação, ciência e tecnologia, com vistas no processo de geração e inovação tecnológica.

A partir da análise das finalidades, características e objetivos dos IFs que traz a oferta de cursos de pós-graduação stricto sensu, surge a questão de como está sendo a participação e 
desempenho dessas instituições no contexto do Sistema de Avaliação da Pós-Graduação. Desta forma, este artigo busca responder as seguintes questões: De que forma se delineia o Sistema de Avaliação de Pós-Graduação? Como está o desempenho dos IFs no processo de Avaliação da Pós-Graduação? Em quais modalidades (Acadêmicas ou Profissionais) e Áreas de Avaliação os IFs submetem propostas de cursos novos? Quais os índices de recomendação por modalidade e área de avaliação das propostas de cursos novos de Pós-Graduação submetidas por IFs? Quais as fragilidades das propostas dos cursos de Pós-Graduação submetidas por IFs? Como foi o desempenho dos Programas de Pós-Graduação ofertados pelos IFs nas avaliações trienais que aconteceram nos anos de 2007, 2010 e 2013, referentes aos respectivos períodos: 2004 a 2006, 2007 a 2009 e 2010 a 2012? 


\title{
2. O SISTEMA NACIONAL DE PÓS-GRADUAÇÃO E O PAPEL DA CAPES
}

A Coordenação de Aperfeiçoamento de Pessoal de Nível Superior - CAPES foi instituída em 1951, por meio do Decreto no 29.741, de 11 de julho de 1951, e tinha como objetivo principal assegurar a existência de pessoal especializado em quantidade e qualidade suficientes para atender às necessidades dos empreendimentos públicos e privados que visassem o desenvolvimento econômico e social do país, além de oferecer aos indivíduos mais capazes, sem recursos próprios, acesso a todas as oportunidades de aperfeiçoamentos (BRASIL, 1951).

\begin{abstract}
A CAPES foi criada num momento em que persistia a tendência a um modelo de ensino superior baseado em escolas profissionais que abrigavam cerca de 50 mil alunos, nas quais a Pós-Graduação stricto sensu era praticamente inexistente. Sua criação significou a iniciativa do Estado brasileiro de se equipar de órgãos e instrumentos para a regulação de diferentes aspectos da vida nacional e para a formulação e execução de políticas que lhe permitissem cumprir um projeto de industrialização intensiva do país (MARTINS, 2002, p. 296-297).
\end{abstract}

A instituição da CAPES surgiu para atender a necessidade urgente de formação de especialistas e pesquisadores nos mais diversos ramos de atividade, desde cientistas qualificados em física, matemática e química a técnicos em finanças e pesquisadores sociais (CAPES, 2015).

Em seu período inicial a CAPES promoveu uma série de iniciativas que tiveram impacto imediato na melhoria do ensino superior e permitiram a implantação da Pós-Graduação Nacional. Além de fornecer bolsas de estudo no país, de modo a viabilizar a participação de estudantes nos cursos de Pós-Graduação, promoveu a reciclagem de docentes, através de Centros Regionais de Treinamento, e procurou também enviar alunos para fazer PósGraduação no exterior. No final dos anos 50, inúmeros estudantes e docentes voltaram ao Brasil e nos anos subsequentes assumiriam a liderança intelectual e científica nas universidades, participando ativamente da implantação dos primeiros cursos de mestrado e de doutorado no país (MARTINS, 2002). 
Em 1964, a Coordenação de Aperfeiçoamento de Pessoal de Nível Superior começou a dar os primeiros passos para atuar como agência de fomento de Pós-Graduação, passando a ser subordinada diretamente ao Ministério da Educação e Cultura.

Em 1965, a partir do modelo de Pós-Graduação em prática nos Estados Unidos da América, as características da Pós-Graduação brasileira foram fixadas pelo Parecer CFE no 977/65, conhecido como "Parecer Sucupira", elaborado pelo professor Newton Sucupira, aprovado pelo Conselho Federal de Educação - CFE. Com o Parecer Sucupira ficou estabelecido o formato institucional da Pós-Graduação nacional, dividindo em dois níveis de formação: o mestrado e doutorado.

O Parecer 977/65, que teve Newton Sucupira como relator, veio conceituar os cursos de pós-graduação, distinguindo dois tipos de pós-graduação: stricto sensu e lato sensu. Na primeira categoria, incluiu o mestrado e o doutorado, cujo objetivo seria de natureza acadêmica, de pesquisa e de cultura, tendo como compromisso o avanço do saber. Esses cursos, ligados à essência da universidade, deveriam constituir atividades regulares e permanentes e conferir diplomas de mestre e de doutor, sendo que esse último corresponderia ao nível mais elevado na hierarquia dos cursos superiores (MARTINS, 2002. p. 300).

A Reforma Universitária de 1968, regulamentada pela Lei 5.540/68, estabeleceu que a indissociabilidade entre ensino, pesquisa e extensão seria característica das universidades. Segundo Martins (2002), a referida lei contribuiu para o crescimento do SNPG ao estabelecer em seu art. 31 que a titulação acadêmica seria considerada um dos principais critérios para ingresso e promoção da carreira universitária.

Para Barros (1998), Reforma Universitária de 68 contribuiu para expansão do SNPG, que, no entanto, era uma expansão quantitativa e não qualitativa, a medida que estava limitada ao aumento do número de docentes pesquisadores.

O valor atribuído aos diplomas resultou na expansão da Pós-Graduação stricto sensu, sem 
normativas e diretrizes tendo como resultado cursos de Pós-Graduação de baixa qualidade. De acordo com Schwartzman (2001), o CFE, que era o órgão responsável pelo credenciamento dos programas de pós-graduação stricto sensu, não conseguiu garantir a qualidade dos programas e, desta forma, as agências de fomento apoiavam as áreas e programas de sua preferência.

Em 1973, foi criado o Grupo de Trabalho para sugerir medidas para a formulação de uma política nacional de Pós-Graduação. Esse grupo propôs a criação do Conselho Nacional de Pós-Graduação - CNPG, órgão interministerial responsável pela formulação e execução da política geral de Pós-Graduação. O Conselho Nacional de Pós-Graduação recebeu a incumbência de elaborar o 1ํ Plano Nacional de Pós-Graduação (I PNPG), aprovado em 11 de novembro de 1974, para o período 1974-79.

O objetivo central do I PNPG era a expansão da Pós-Graduação, visando à capacitação dos docentes das instituições de ensino superior, e suas principais metas eram o aumento da titulação e de vagas nos cursos de mestrado e de doutorado.

De acordo com Martins (2002), a CAPES passou a desempenhar um papel importante na implantação da política de Pós-Graduação ao assumir a responsabilidade de organizar o Programa Institucional de Capacitação Docente (PICD), previsto no 1ำ Plano Nacional de PósGraduação (PNPG 1974-1979). O objetivo do PICD era estimular as instituições de ensino superior a desenvolver seus recursos humanos por meio de cursos de Pós-Graduação stricto sensu.

Com a expansão da Pós-Graduação, associada a incapacidade operacional do CFE em reconhecer e avaliar os programas de pós-graduação, as agências de fomento não dispunham de muitas informações para selecionar os programas que seriam fomentados. Com o objetivo de solucionar esta questão, a CAPES organizou a primeira avaliação da PósGraduação em 1976. A avaliação teve como foco a produção científica dos docentes 
vinculados aos programas.

Em 1981, o CNPG foi extinto e a CAPES foi reconhecida como órgão responsável pela elaboração do Plano Nacional de Pós-Graduação stricto sensu, deixando de ser somente um órgão de distribuição de bolsas e passando a se transformar efetivamente em agência de fomento para os programas de Pós-Graduação. Enquanto se aprimorava o processo de avaliação da Pós-Graduação, foram lançados outros planos nacionais de Pós-Graduação com o objetivo de planejar e regulamentar a expansão do SNPG.

O II PNPG (1982-1985) teve como ênfase a qualidade do ensino superior, mais especificamente a qualidade da Pós-Graduação, destacando a necessidade de consolidar o processo de avaliação dos cursos de Pós-Graduação e a maior participação da comunidade científica nas decisões sobre a política de Pós-Graduação.

Com a implementação e aperfeiçoamento do processo de avaliação dos programas de PósGraduação, a distribuição na concessão de bolsas de mestrados e doutorados da CAPES passa a seguir as notas atribuídas no processo de avaliação (CAPES, 2002).

O III PNPG (1986-1989) trouxe a necessidade de mudança no paradigma na educação superior, alterando o foco da formação de profissionais para a formação de pesquisadores, e teve como principais objetivos a consolidação e melhoria da qualidade dos programas de Pós-Graduação; o desenvolvimento da pesquisa nas universidades; e a integração da PósGraduação ao Sistema Nacional de Ciência e Tecnologia.

Em 1990, a CAPES passa a ser órgão específico do Ministério da Educação e posteriormente, em 1992, foi instituída como Fundação Pública, com atribuição do acompanhamento e avaliação dos cursos de Pós-Graduação stricto sensu no Brasil.

O IV PNPG teve sua elaboração iniciada em 1996, coincidindo com a Reforma Política do 
Estado Brasileiro durante a gestão do Governo de Fernando Henrique Cardoso e não chegou a ser finalizado.

\begin{abstract}
Uma série de circunstâncias, envolvendo restrições orçamentárias e falta de articulação entre as agências de fomento nacional, impediu que o Documento Final se concretizasse num efetivo Plano Nacional de PósGraduação. No entanto, diversas recomendações que subsidiaram as discussões foram implantadas pela Diretoria da CAPES ao longo do período, tais como expansão do sistema, diversificação do modelo de pós-graduação, mudanças no processo de avaliação e inserção internacional da pósgraduação (CAPES, 2004, PNPG, p. 17-18).
\end{abstract}

Em 1995, a CAPES determinou a implantação de procedimentos apropriados para a recomendação, acompanhamento e avaliação dos cursos de mestrado voltados para a formação profissional, por meio da Portaria no. 47/95. Assim, surgia a modalidade de cursos de Pós-Graduação stricto sensu profissional. Em Janeiro de 1999, a CAPES publicou a Portaria no 80 que dispôs sobre o reconhecimento dos mestrados profissionais.

Desta forma o SNPG passou a ser composto por duas modalidades de cursos de PósGraduação stricto sensu, que são as modalidades acadêmica e profissional.

\title{
2.1. Modalidade de Programas de Pós-Graduação Stricto Sensu
}

A modalidade de Pós-Graduação stricto sensu acadêmica é a modalidade considerada mais tradicional. É composta pelos níveis de mestrado e doutorado e seu objetivo é formar pesquisadores com o foco inicial na academia. De acordo com o Parecer CFE no 977/65, a modalidade de Pós-Graduação stricto sensu acadêmica tem por finalidade proporcionar formação científica ou cultural ampla e aprofundada, desenvolvendo a capacidade de pesquisa e poder criados nos diferentes ramos do saber.

A diferença entre as duas modalidades de Cursos de Pós-Graduação é que a modalidade profissional é a designação do mestrado profissional com ênfase em estudos e técnicas diretamente voltadas ao desempenho de um alto nível de qualificação profissional. Esta 
ênfase é uma das diferenças em relação aos Cursos de Pós-Graduação Acadêmicos (Parecer CNE/CES 79/2002).

A modalidade de Pós-Graduação stricto sensu profissional é considerada recente, mesmo o Parecer CFE no 977/65 já propondo a criação de cursos de Pós-Graduação orientados à capacitação profissional, a existência legal do mestrado profissional, enquanto prática acadêmica institucionalizada decorre da década de 90.

O mestrado profissional teve sua primeira regulamentação pela CAPES por meio da Portaria CAPES no 47, de 17 de outubro de 1995.

O mestrado profissional nasce regulamentado desde 1995, seguindo-se portarias e resoluções que tentam estabelecer as diferenças entre cursos acadêmicos e profissionais. Com formato e denominação polêmicos, o MP esbarra na concepção acadêmica da Pós-Graduação, sedimentada por práticas e modelos tradicionais (FISCHER, 2005, p. 25).

De acordo com Fischer (2005), uma das diferenças é que o Mestrado Profissional não se trata de um tipo de formação pensada em termos de linhas de pesquisa, mas em termos de área de competência para a solução de problemas e para a inovação. No entanto, este foco não deve ser motivo para criar uma hierarquização entre mestrados acadêmicos e profissionais. As duas modalidades estão no mesmo nível hierárquico.

O objetivo do mestrado profissional expresso na Portaria CAPES no 80/98 era a formação de profissionais pós-graduados aptos a elaborar novas técnicas e processos, com desempenho diferenciado de egressos dos cursos de mestrado que visem preferencialmente a um aprofundamento de conhecimentos ou técnicas de pesquisa científica, tecnológica ou artística.

Onze anos depois, a Portaria MEC no 17, de 28 de dezembro de 2009, amplia os objetivos do Mestrado Profissional: 
I - capacitar profissionais qualificados para o exercício da prática profissional avançada e transformadora de procedimentos, visando atender demandas sociais, organizacionais ou profissionais e do mercado de trabalho; II transferir conhecimento para a sociedade, atendendo demandas específicas e de arranjos produtivos com vistas ao desenvolvimento nacional, regional ou local; III - promover a articulação integrada da formação profissional com entidades demandantes de naturezas diversas, visando melhorar a eficácia e a eficiência das organizações públicas e privadas por meio da solução de problemas e geração e aplicação de processos de inovação apropriados; IV contribuir para agregar competitividade e aumentar a produtividade em empresas, organizações públicas e privadas (BRASIL, 2009).

A Portaria Normativa MEC no 17/2009 também transforma o mestrado profissional em política de Estado com indução para cursos em rede nacional, regula a oferta de curso mediante chamadas públicas, implanta avaliação distinta dos cursos acadêmicos, permite a atuação de docentes que não tenham o título de doutor, mas que tenham reconhecida experiência profissional, e amplia os formatos de trabalho de conclusão de curso dos alunos, que vão além da dissertação.

Com relação ao fomento de cursos na modalidade profissional, a Portaria MEC no 17/2009 restringe a concessão de bolsas de estudos para mestrados profissionais em áreas priorizadas: "salvo em áreas excepcionalmente priorizadas, o mestrado profissional não pressupõe, a qualquer título, a concessão de bolsas de estudos pela CAPES" (art. 11).

Atualmente os programas priorizados e contemplados com bolsas de estudos são os Mestrados Profissionais em Rede Nacional - PROFs voltados para formação de professores da Educação Básica e professores da Rede Pública da Educação Básica, regularmente matriculados em cursos de mestrado profissional ofertados pelas instituições de ensino superior, devidamente recomendados pela CAPES, conforme previsto nas Portarias CAPES no 289 e 478 de 2011.

De acordo com Fischer, Waiandt e Fonseca (2011), a instituição da modalidade da PósGraduação stricto sensu na modalidade profissional é fruto da política empreendida pelo 
governo federal a partir dos anos 2000 na tentativa de configurar a educação profissional como um eixo conformativo, institucionalizando-se tanto nos Institutos Federais de Ciência e Tecnologia com todos os níveis de ensino (da Educação Básica à Pós-Graduação) quanto nas Instituições Educacionais públicas e privadas com os mestrados profissionais.

O V PNPG (2005-2010) estimulou o fortalecimento de quadros para mercados "não acadêmicos", especificando as empresas, os órgãos de governo e organizações não governamentais e movimentos sociais; como as instituições-alvo dos egressos da PósGraduação.

Em 2007, a Lei no 11.502, de 11 de julho, estabelece novas atribuições para a CAPES, que além de ser responsável pela coordenação do Sistema Nacional de Pós-Graduação passa também a ter atribuição de indução e fomento da formação inicial e continuada de professores para a Educação Básica.

A CAPES vem desempenhando, desde sua criação, um papel fundamental na expansão e consolidação da Pós-Graduação stricto sensu (mestrados profissionais e mestrados e doutorados acadêmicos). Atualmente, de acordo o artigo 1ㅇ do seu estatuto, tem por finalidade subsidiar o Ministério da Educação na formulação de políticas para PósGraduação, coordenar o sistema de Pós-Graduação e avaliar os cursos desse nível, e estimular, mediante bolsas de estudo, auxílios e outros mecanismos, a formação de recursos humanos altamente qualificados para a docência de grau superior, a pesquisa e o atendimento da demanda dos setores público e privado. 


\title{
3. O SISTEMA DE AVALIAÇÃO DA PÓS-GRADUAÇÃO
}

Com o crescimento dos cursos de Pós-Graduação stricto sensu, surgiram a preocupação com qualidade da geração de conhecimento e da pesquisa e a necessidade de implantação de instrumentos de controle de qualidade. Esta necessidade acabou desencadeando o Sistema de Avaliação da Pós-Graduação implantado pela CAPES.

\begin{abstract}
A reforma de 1968 e os substanciosos recursos oferecidos pelas agências de financiamento da Pós-Graduação e da pesquisa (CAPES, CNPq e FINEP), dentro dos sucessivos Planos de Desenvolvimento Científico e Tecnológico, profissionalizaram o sistema universitário, com a implantação dos regimes de tempo integral e de dedicação exclusiva e, sobretudo, implementaram uma consistente política de Pós-Graduação, com a avaliação pelos pares sob a coordenação da CAPES (TRINDADE, 2002, p. 150).
\end{abstract}

Desta forma, foi implantado um sistema de avaliação e acompanhamento do SNPG pela CAPES que foi reiterado e inserido na formulação e lançamento do 1ㅇ PNPG. No 2 PNPG (1982-1985), o objetivo da CAPES continuou sendo a formação qualificada de recursos humanos para atender as demandas públicas e privadas, além da capacitação docente. Já em suas diretrizes, o plano enfatizou a qualidade do ensino superior e principalmente a qualidade da Pós-Graduação, fazendo-se necessário aprimorar a avaliação que sutilmente já vinha sendo realizada anteriormente com a contribuição da sociedade científica. Em 1976, a CAPES decidiu implantar um sistema de avaliação dos cursos e programas das universidades.

De acordo com Cordova, Gusso e Luna (1986), a decisão da CAPES deu-se, em grande parte, em função do crescimento acentuado dos cursos de mestrado e doutorado no país (após implantação oficial da Pós-Graduação em 1965), que poderia colocar em risco a qualidade acadêmica desses cursos; bem como do clamor da comunidade acadêmica. Esse clamor referia-se à qualidade de ensino e não a um pedido de avaliação; porém, a CAPES entendeu que era com base na avaliação que se encontrariam as causas que justificariam as providências a serem tomadas para se chegar aos níveis de qualidade almejados e reclamados. 
O Sistema de Avaliação dos cursos e programas de Pós-Graduação stricto sensu implantado pela CAPES, teve inicialmente como finalidades: identificar os acertos, os erros e os problemas dos cursos; orientar-se no planejamento ou na formulação de políticas; alocar e distribuir recursos; e assegurar a qualidade do ensino e da produção científica.

[...] a burocratização das universidades que, transformadas em pesadas organizações, exigiam a consequente regulação e controle das atividades desenvolvidas, principalmente nos programas de Pós-Graduação. Nessas circunstâncias, e em relação à Pós-Graduação, cria-se a necessidade de avaliação da pesquisa ali desenvolvida. A CAPES encarregou-se deste papel e implantou, em 1976, a sistemática de avaliação por meio de comissões de consultores - a avaliação por pares -, sendo a primeira delas realizada em 1978 (HOSTINS, 2006, p. 138).

Para Martins (2002), o Sistema de Avaliação da Pós-Graduação desempenha papel essencial na melhoria, ampliação e consolidação da Pós-Graduação e dos estudos científicos e tecnológicos no país, além de subsidiar deliberações concernentes a programas e políticas de incentivo à Pós-Graduação, como distribuição de bolsas. A avaliação iniciou-se em virtude da distribuição das bolsas que passou de concessão individual a institucional.

Atualmente o Sistema Nacional de Pós-Graduação é composto pelos programas de PósGraduação recomendados pela CAPES e distribuídos entre as 48 áreas de avaliação. Cada área de Avaliação possui uma Coordenação de Área, composta por coordenador e adjuntos, e consultores pertencentes e atuantes dentro das próprias áreas. A escolha dos coordenadores é feita por indicação da comunidade científica e finalizada pelo Conselho Superior e a Presidência da CAPES. As 48 áreas de avaliação formulam Documentos de Área e Requisitos de Cursos Novos que norteiam os programas de Pós-Graduação tanto na avaliação de cursos novos como no acompanhamento dos Programas de Pós-Graduação já recomendados e ativos no SNPG. Estes Documentos contêm os principais indicadores de avaliação das áreas e as expectativas e orientações para o crescimento qualitativo dos programas.

O Sistema de Avaliação da Pós-Graduação compreende-se em dois processos que se referem à Entrada e Permanência dos cursos de Pós-Graduação no SNPG (Figura 1) e valoriza, 
sobretudo, aspectos ligados à qualificação do corpo docente, pesquisa e publicação científica.

Figura 1. Processos do Sistema de Avaliação da Pós-Graduação.

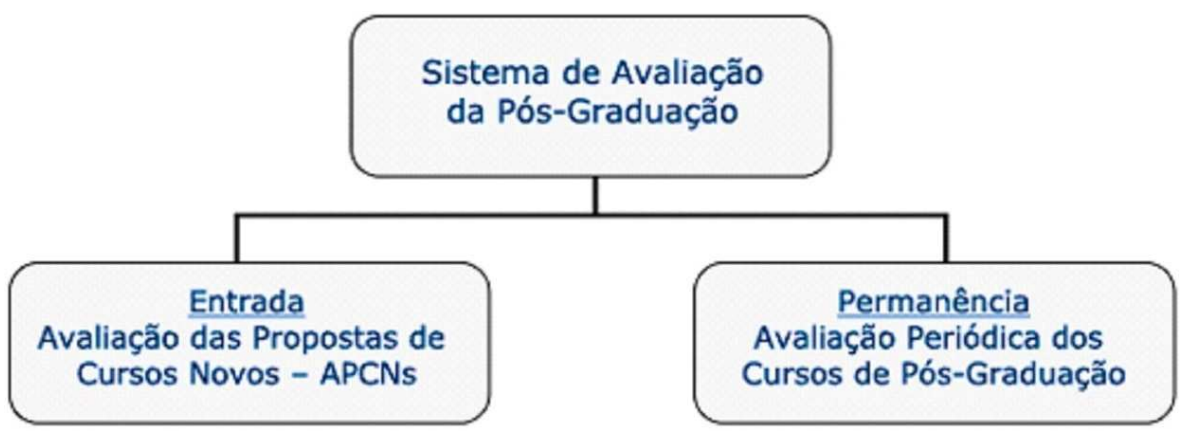

Fonte: CAPES (2015).

\subsection{Processo de Entrada no Sistema Nacional de Pós-Graduação}

O processo de entrada no SNPG, que consiste na Avaliação de Propostas de Cursos Novos APCN é composto pelas seguintes etapas: Etapa 1 - Submissão das propostas à CAPES: as propostas são elaboradas pelas Instituições e enviadas à CAPES por meio da Plataforma Sucupira (ferramenta on-line para coletar informações, realizar análises, avaliações e servir como base de referência do SNPG) observando os requisitos pré-definidos pelas áreas de avaliação; Etapa 2 - Análise pelas Comissões de Área de avaliação: as propostas são analisadas por comissões de consultores especialistas ad hoc, que emitem relatórios com parecer e nota (escala de 1 a 7) para cada curso; Etapa 3 - Análise e Decisão pelo Conselho Técnico Cientifico da Educação Superior - CTC-ES: o relatório da Comissão de Área e a proposta são analisados por relatores membros do CTC-ES, que apresenta parecer conclusivo ao colegiado. O CTC-ES aprecia o parecer e decide pela recomendação ou não recomendação do curso. Para recomendação do curso é necessário ter nota igual ou superior a 3; Etapa 4 Deliberação do Conselho Nacional de Educação - CNE: o parecer do CTC-ES é encaminhado ao CNE/MEC para deliberação sobre a autorização e reconhecimento dos cursos.

A legislação vigente que fixa normas para a avaliação das propostas de cursos novos de PósGraduação stricto sensu é a Portaria CAPES no 91/2015, visando à autorização e ao 
reconhecimento de cursos para a entrada no SNPG. Segundo seu texto, somente têm validade nacional os diplomas de mestrado e doutorado reconhecidos pelo CNE/MEC, sendo esse ato de reconhecimento baseado na avaliação da proposta realizada pela CAPES.

O Sistema de Avaliação da Pós-Graduação realizado pela CAPES possui duas instâncias: as Comissões de Área e o CTC-ES. Cabem às Comissões de Área a análise e avaliação dos programas de Pós-Graduação e a formulação de parecer justificado sobre a qualidade da proposta, no caso de cursos novos. Já ao CTC-ES cabe a função de, embasados pelos pareceres elaborados pelas Comissões de Área, deliberar sobre as notas atribuídas.

A avaliação das propostas de cursos novos é registrada em fichas de avaliação estruturadas em 5 quesitos, abordando: Comprometimento institucional; Infraestrutura; Proposta do Curso; Dimensão e regime de trabalho do corpo docente; e Produtividade docente e consolidação da capacidade de pesquisa (Quadro 1).

Quadro 1. Quesitos da Ficha de Avaliação de Curso Novo (Profissionais e Acadêmicos) - DAV/CAPES.

\begin{tabular}{|l|l|}
\hline \multicolumn{1}{|c|}{ Aspecto considerado } & \multicolumn{1}{c|}{ Quesitos } \\
\hline $\begin{array}{l}\text { Condições oferecidas } \\
\text { pela instituição }\end{array}$ & $\begin{array}{l}\text { 1. A proposta contém indicadores de que a instituição está comprometida com a } \\
\text { implantação e o êxito do curso? }\end{array}$ \\
\cline { 2 - 3 } & $\begin{array}{l}\text { 2. O programa dispõe da infraestrutura - instalações físicas, laboratórios, biblioteca, } \\
\text { recursos de informática... - essencial para o adequado funcionamento do curso? }\end{array}$ \\
\hline Proposta do curso & $\begin{array}{l}\text { 3. A proposta é adequadamente concebida, apresentando objetivos, áreas de } \\
\text { concentração, linhas de Pesquisas (*) e estrutura curricular bem definidos e } \\
\text { articulados? } \\
(*) \text { Para Mestrado Profissionalizante onde lê-se 'linhas de pesquisas', leia-se 'linhas } \\
\text { de atuação científico/tecnológicas'. }\end{array}$ \\
\hline $\begin{array}{l}\text { Dimensão e regime do } \\
\text { trabalho do corpo } \\
\text { docente }\end{array}$ & $\begin{array}{l}\text { 4. O número de docentes, especialmente daqueles com tempo integral na } \\
\text { instituição, é suficiente para dar sustentação às atividades do curso, consideradas as } \\
\text { áreas de concentração e número de alunos previstos? }\end{array}$ \\
\hline $\begin{array}{l}\text { Produtividade docente } \\
\text { e consolidação da } \\
\text { capacidade de pesquisa }\end{array}$ & $\begin{array}{l}\text { 5. O programa conta, especialmente no que se refere ao seu Núcleo de Docentes } \\
\text { Permanentes, com grupo de pesquisadores com (*) maturidade científica, } \\
\text { demonstrada pela sua produção nos últimos três anos, e com nível de integração } \\
\text { que permitam o adequado desenvolvimento dos projetos de pesquisa e das } \\
\text { atividades ensino e orientação previstos. } \\
(*) \text { Para Mestrado Profissionalizante onde lê-se 'maturidade científica', leia-se } \\
\text { 'maturidade científica/tecnológica'. }\end{array}$ \\
\hline
\end{tabular}
Fonte: SNPG/DAV/CAPES. 
Após a recomendação e reconhecimento do curso de Pós-Graduação, o referido curso fará parte do SNPG e passará pelo processo de permanência no Sistema, que consiste no acompanhamento e reavaliação a cada quatro anos. Até o ano de 2013 , as avaliações aconteciam a cada triênio. Em dezembro de 2014, o Conselho Superior da CAPES, em sua 68 a reunião, decidiu que a avaliação dos cursos de Pós-Graduação stricto sensu do SNPG passaria a ser quadrienal, conforme Resolução do Conselho Superior da CAPES no 05, de 11 de dezembro de 2014.

\subsection{Processo de Permanência no Sistema Nacional de Pós-Graduação}

O processo de permanência no SNPG, que consiste na Avaliação Quadrienal, é composto pelas seguintes etapas: Etapa 1 - Coleta das Informações: as Instituições prestam informações dos programas de Pós-Graduação stricto sensu anualmente por meio da Plataforma Sucupira; Etapa 2 - Tratamento das Informações: As informações fornecidas pelas Instituições são consolidadas pelo corpo técnico da CAPES; Etapa 3 - Análise pelas Comissões de Área de avaliação: os Programas são analisados por comissões de consultores especialistas ad hoc, que emitem relatórios com parecer e nota para cada curso, numa escala de 1 a 7; Etapa 4 - Análise e Decisão pelo CTC/ES: os relatórios das Comissões de Área são analisados por relatores membros do CTC-ES, que apresenta parecer conclusivo ao colegiado; o CTC-ES aprecia o parecer e decide pela nota do curso; Etapa 5 - Deliberação do CNE/MEC: o parecer do CTC-ES é encaminhado ao CNE/MEC para deliberação sobre a renovação de reconhecimento dos cursos.

A escala de notas é de 1 a 7 , sendo que 1 e 2 descredenciam os programas de PósGraduação. As notas 6 e 7 são atribuídas a programas na modalidade acadêmica com destaque no SNPG por sua excelência e inserções nacional e internacional.

A avaliação dos programas de Pós-Graduação é registrada em fichas de avaliação estruturadas em 5 quesitos, abordando: Proposta do Programa; Corpo docente; Corpo Discente; Teses e Dissertações; Produção Intelectual; e Inserção social (Quadros 2 e 3). Os 
Programas Acadêmicos e Profissionais possuem fichas de avaliação distintas.

Quadro 2. Quesitos da Ficha de Avaliação dos Programas de Pós-Graduação (Acadêmicos) - DAV/CAPES.

\begin{tabular}{|c|c|}
\hline Quesitos & Itens \\
\hline \multirow[t]{3}{*}{ 1. Proposta do Programa } & $\begin{array}{l}\text { 1.1. Coerência, consistência, abrangência e atualização das áreas de concentração, } \\
\text { linhas de pesquisa, projetos em andamento e proposta curricular. }\end{array}$ \\
\hline & $\begin{array}{l}\text { 1.2. Planejamento do programa com vistas a seu desenvolvimento futuro, } \\
\text { contemplando os desafios internacionais da área na produção do conhecimento, } \\
\text { seus propósitos na melhor formação de seus alunos, suas metas quanto à inserção } \\
\text { social mais rica dos seus egressos, conforme os parâmetros da área. }\end{array}$ \\
\hline & 1.3. Infraestrutura para ensino, pesquisa e, se for o caso, extensão. \\
\hline \multirow[t]{4}{*}{ 2. Corpo Docente } & $\begin{array}{l}\text { 2.1. Perfil do corpo docente, considerando experiência como pesquisador e/ou } \\
\text { profissional, titulação e sua adequação à Proposta do Programa. }\end{array}$ \\
\hline & $\begin{array}{l}\text { 2.2. Adequação da dimensão, composição e dedicação dos docentes permanentes } \\
\text { para o desenvolvimento das atividades de pesquisa e formação do Programa. }\end{array}$ \\
\hline & $\begin{array}{l}\text { 2.3. Distribuição das atividades de pesquisa, projetos de desenvolvimento e } \\
\text { inovação e de formação entre os docentes do Programa. }\end{array}$ \\
\hline & $\begin{array}{l}\text { 2.4. Contribuição dos docentes para atividades de ensino e/ou de pesquisa na } \\
\text { graduação, com atenção tanto à repercussão que este item pode ter na formação } \\
\text { de futuros ingressantes na PG, quanto (conforme a área) na formação de } \\
\text { profissionais mais capacitados no plano. }\end{array}$ \\
\hline \multirow[t]{4}{*}{$\begin{array}{l}\text { 3. Corpo Discente, Teses } \\
\text { e Dissertações }\end{array}$} & $\begin{array}{l}\text { 3.1. Quantidade de teses e dissertações defendidas no período de avaliação, em } \\
\text { relação ao corpo docente permanente e à dimensão do corpo discente. }\end{array}$ \\
\hline & $\begin{array}{l}\text { 3.2. Distribuição das orientações das teses e dissertações defendidas no período de } \\
\text { avaliação em relação aos docentes do programa. }\end{array}$ \\
\hline & $\begin{array}{l}\text { 3.3. Qualidade das Teses e Dissertações e da produção de discentes autores da Pós- } \\
\text { Graduação e da graduação (no caso de IES com curso de graduação na área) na } \\
\text { produção científica do programa, aferida por publicações e outros indicadores } \\
\text { pertinentes à área. }\end{array}$ \\
\hline & $\begin{array}{l}\text { 3.4. Eficiência do Programa na formação de mestres e doutores bolsistas: Tempo de } \\
\text { formação de mestres e doutores e percentual de bolsistas titulados. }\end{array}$ \\
\hline \multirow[t]{3}{*}{ 4. Produção Intelectual } & 4.1. Publicações qualificadas do Programa por docente permanente. \\
\hline & $\begin{array}{l}\text { 4.2. Distribuição de publicações qualificadas em relação ao corpo docente } \\
\text { permanente do Programa. }\end{array}$ \\
\hline & 4.3. Produção técnica, patentes e outras produções consideradas relevantes. \\
\hline \multirow[t]{3}{*}{ 5. Inserção Social } & 5.1. Inserção e impacto regional e (ou) nacional do programa. \\
\hline & $\begin{array}{l}\text { 5.2. Integração e cooperação com outros programas e centros de pesquisa e } \\
\text { desenvolvimento profissional relacionados à área de conhecimento do programa, } \\
\text { com vistas ao desenvolvimento da pesquisa e da Pós-Graduação. }\end{array}$ \\
\hline & 5.3. Visibilidade ou transparência dada pelo programa à sua atuação. \\
\hline
\end{tabular}

Fonte: SNPG/DAV/CAPES. 
FORMAÇÃO INICIAL E CONTINUADA DE PROFESSORES DA EDUCAÇÃO BÁSICA

5 anos divulgando e popularizando ciência

Quadro 3. Quesitos da Ficha de Avaliação dos Programas de Pós-Graduação (Profissionais) - DAV/CAPES.

\begin{tabular}{|c|c|}
\hline Quesitos & Itens \\
\hline \multirow[t]{4}{*}{ 1. Proposta do Programa } & $\begin{array}{l}\text { 1.1. Coerência, consistência, abrangência e atualização da(s) área(s) de } \\
\text { concentração, linha(s) de atuação, projetos em andamento, proposta curricular com } \\
\text { os objetivos do Programa. }\end{array}$ \\
\hline & $\begin{array}{l}\text { 1.2. Coerência, consistência e abrangência dos mecanismos de interação efetiva } \\
\text { com outras instituições, atendendo a demandas sociais, organizacionais ou } \\
\text { profissionais. }\end{array}$ \\
\hline & 1.3. Infraestrutura para ensino, pesquisa e administração. \\
\hline & $\begin{array}{l}\text { 1.4. Planejamento do Programa visando ao atendimento de demandas atuais ou } \\
\text { futuras de desenvolvimento nacional, regional ou local, por meio da formação de } \\
\text { profissionais capacitados para a solução de problemas e práticas de forma } \\
\text { inovadora. }\end{array}$ \\
\hline \multirow[t]{3}{*}{ 2. Corpo Docente } & $\begin{array}{l}\text { 2.1. Perfil do corpo docente, considerando experiência como pesquisador e/ou } \\
\text { profissional, titulação e sua adequação à Proposta do Programa. }\end{array}$ \\
\hline & $\begin{array}{l}\text { 2.2. Adequação da dimensão, composição e dedicação dos docentes permanentes } \\
\text { para o desenvolvimento das atividades de pesquisa e formação do Programa. }\end{array}$ \\
\hline & $\begin{array}{l}\text { 2.3. Distribuição das atividades de pesquisa, projetos de desenvolvimento e } \\
\text { inovação e de formação entre os docentes do Programa. }\end{array}$ \\
\hline \multirow[t]{3}{*}{$\begin{array}{l}\text { 3. Corpo Discente, Teses } \\
\text { e Dissertações }\end{array}$} & $\begin{array}{l}\text { 3.1. Quantidade de trabalhos de conclusão (MP) aprovados no período e sua } \\
\text { distribuição em relação ao corpo discente titulado e ao corpo docente do programa. }\end{array}$ \\
\hline & 3.2. Qualidade dos trabalhos de conclusão produzidos por discentes e egressos. \\
\hline & 3.3. Aplicabilidade dos trabalhos produzidos. \\
\hline \multirow[t]{4}{*}{ 4. Produção Intelectual } & 4.1. Publicações qualificadas do Programa por docente. \\
\hline & $\begin{array}{l}\text { 4.2. Produção artística, técnica, patentes, inovações e outras produções } \\
\text { consideradas relevantes. }\end{array}$ \\
\hline & $\begin{array}{l}\text { 4.3. Distribuição da produção científica e técnica ou artística em relação ao corpo } \\
\text { docente permanente do programa. }\end{array}$ \\
\hline & $\begin{array}{l}\text { 4.4. Articulação da produção artística, técnica e científica entre si e com a proposta } \\
\text { do programa. }\end{array}$ \\
\hline \multirow[t]{4}{*}{ 5. Inserção Social } & 5.1. Impacto do Programa. \\
\hline & $\begin{array}{l}\text { 5.2. Integração e cooperação com outros Cursos/Programas com vistas ao } \\
\text { desenvolvimento da Pós-Graduação. }\end{array}$ \\
\hline & $\begin{array}{l}\text { 5.3. Integração e cooperação com organizações e/ou instituições setoriais } \\
\text { relacionados à área de conhecimento do Programa, com vistas ao desenvolvimento } \\
\text { de novas soluções, práticas, produtos ou serviços nos ambientes profissional e/ou } \\
\text { acadêmico. }\end{array}$ \\
\hline & 5.4. Divulgação e transparência das atividades e da atuação do Programa. \\
\hline
\end{tabular}

Fonte: SNPG/DAV/CAPES. 
Os quesitos são ponderados por cada área de avaliação, seguindo orientações gerais do CTCES e avaliados como Muito Bom, Bom, Regular ou Fraco. Após a avaliação inicial, são elegíveis às notas 6 e 7 os programas de Pós-Graduação com o nível de Doutorado que obtiverem nota 5 e conceito Muito Bom em todos os quesitos.

$\mathrm{Na}$ avaliação dos programas de Pós-Graduação elegíveis às notas 6 e 7, mais um quesito é avaliado referente ao nível de desempenho (formação de doutores e produção intelectual) diferenciado em relação aos demais programas da área e desempenho equivalente ao dos centros internacionais de excelência na área (internacionalização e liderança).

Como os Programas de Pós-Graduação na modalidade profissional não possuem o nível de doutorado, a nota máxima atingida por programas nesta modalidade é 5 .

Tendo em vista as peculiaridades dos Programas de Pós-Graduação stricto sensu nas modalidades acadêmicas e profissionais, a avaliação nos processos de entrada e de permanência no SNPG é realizada por comissões distintas e seguindo critérios próprios para cada modalidade. 


\section{CRIAÇÃO DOS IFS E A SUA ATUAÇÃO NO SISTEMA NACIONAL DE PÓS-GRADUAÇÃO}

Após abordar sobre o papel da CAPES no SNPG e o processo de avaliação da Pós-Graduação implantado pela CAPES como instrumento de controle e qualidade dos cursos de PósGraduação stricto sensu, cabe contextualizar a participação das Instituições de Educação Profissional e Tecnológica neste processo, tendo em vista que inicialmente a Pós-Graduação stricto sensu era voltada para as Universidades.

De acordo com Almeida (2011), ao longo de quarenta e cinco anos de existência, que corresponde ao período de 1965 a 2010, o Sistema Nacional de Pós-Graduação - SNPG fundamentou-se nas universidades públicas, que foram as responsáveis pela formação considerável de mestre e doutores e foram o locus principal de produção de conhecimento científico e tecnológico de reconhecimento internacional.

A partir de 2008, quando são criados os IFs, os Institutos Federais surgem como uma nova instituição que passa também a ter uma participação mais ativa no SNPG, tendo em vista a atribuição, prevista em lei, de ofertar de cursos de Pós-Graduação stricto sensu.

A Rede Federal de Educação Profissional, Científica e Tecnológica foi instituída em 2008 e teve origem a partir das primeiras escolas de caráter profissional no Brasil, as Escolas de Aprendizes Artífices, criadas em 1909 pelo presidente Nilo Peçanha. Segundo Manfredi (2002), foi criada uma rede de 19 Escolas de Aprendizes Artífices, dando origem à rede federal que culminou nas Escolas Técnicas e, posteriormente, nos CEFETs. Essas escolas eram voltadas para o ensino profissional, primário e gratuito destinada aos "desafortunados" ou "desvalidos da sorte".

As Escolas de Aprendizes Artífices passaram a ser conhecidas como Liceus Industriais e, em 1937 e em 1942, os Liceus tornaram-se Escolas Industriais e Técnicas e ofereciam a formação profissional em nível equivalente ao secundário (LIMA, 2012). 
As Escolas Industriais e Técnicas foram denominadas Escolas Técnicas Federais - ETF em 1959, na forma de autarquias com autonomia didática e de gestão. O objetivo das ETF era "proporcionar base de cultura geral e iniciação técnica que permitam ao educando integrarse na comunidade e participar do trabalho produtivo ou prosseguir seus estudos" (BRASIL, 1959).

De acordo com Silva (2009), os primeiros Centros Federais de Educação Tecnológica - CEFETs surgiram em 1978, a partir da transformação nas Escolas Técnicas Federais do Paraná, de Minas Gerais e do Rio de Janeiro. Os CEFETs equiparavam-se aos centros universitários, no âmbito da oferta da educação superior.

A década de 90 é marcada pela expansão dos CEFETs, período em que várias outras Escolas Técnicas Federais e Escolas Agrotécnicas tornam-se CEFETs. Um marco dessa expansão é a Lei no 8.948/94, que dispõe sobre a instituição do Sistema Nacional de Educação Tecnológica. De acordo com a referida lei, as Escolas Técnicas Federais seriam transformadas em CEFETs e as Escolas Agrotécnicas Federais poderiam ser transformadas em CEFETs após processo de avaliação de desempenho a ser desenvolvido sob a coordenação do MEC.

Em 2005, o CEFET-PR foi transformado em Universidade Tecnológica Federal do Paraná UTFPR por meio da Lei 11.184/2005. Quando a proposta dos IFs surgiu, o objetivo dos CEFETs era transformarem-se em universidades tecnológicas, a exemplo do que havia acontecido com o CEFET-PR; no entanto isto não aconteceu e, em 2007, iniciou-se o processo de criação dos Institutos Federais de Educação, Ciência e Tecnologia - IFs, que seriam oriundos da transformação CEFETs, UNEDs, Escolas Vinculadas, Escolas Agrotécnicas e Escolas Técnicas Federais.

O Decreto no 6.095/2007 foi o primeiro dispositivo legal a tratar do tema da criação dos IFs. De acordo com este decreto, o objetivo do Ministério da Educação era estimular o processo de reorganização das instituições federais de educação profissional e tecnológica, a fim de 
que atuassem de forma integrada regionalmente e que esta reorganização seria pelo modelo de Instituto Federal de Educação, Ciência e Tecnologia (BRASIL, 2007).

Quando o processo de criação dos IFs se iniciou, a Rede Federal de Ensino Tecnológico contava com 36 Escolas Agrotécnicas, 33 CEFETs com suas 58 Unidades de Ensino Descentralizadas (UNEDs), 32 Escolas Vinculadas, uma Universidade Tecnológica Federal e uma Escola Técnica Federal (BRASIL, 2008).

O Ministério da Educação emitiu a Chamada Pública MEC/SETEC 02/2007, em 12 de dezembro de 2007, com o objetivo de acolher, num prazo de 90 dias, propostas de constituição dos IFs. O primeiro item da contextualização da chamada pública expressa a intencionalidade política do projeto, que coloca a implantação dos IFs como uma das ações do Plano de Desenvolvimento da Educação - PDE.

\begin{abstract}
A implantação dos Institutos Federais de Educação, Ciência e Tecnologia constitui-se em uma das ações de maior relevo do Plano de Desenvolvimento da Educação - PDE, na medida em que tornará mais substantiva a contribuição da rede federal de educação profissional e tecnológica ao desenvolvimento sócio-econômico do conjunto de regiões dispostas no território brasileiro, a partir do acolhimento de um público historicamente colocado a margem das políticas de formação para o trabalho, da pesquisa aplicada destinada à elevação do potencial das atividades produtivas locais e da democratização do conhecimento à comunidade em todas as suas representações (BRASIL, 2007).
\end{abstract}

Em junho de 2008, foi lançado o documento "Concepções e Diretrizes dos Institutos Federais de Educação, Ciência e Tecnologia", o qual apresentava os fundamentos dos IFs, e, em dezembro, foram criados os Institutos Federais de Educação, Ciência e Tecnologia e instituída a Rede Federal de Educação Profissional, Científica e Tecnológica, por meio da Lei no 11.892, de 29 de dezembro de 2008.

A lei no 11.892/08 criou 38 IFs, com a finalidade de ofertar educação profissional e tecnológica em todos os níveis e modalidades e promover a integração e a verticalização da educação profissional, desde a educação básica até a educação superior, otimizando a infraestrutura física, os 
quadros de pessoal e os recursos de gestão. Segundo a legislação que o instituiu, o Instituto Federal deve constituir-se como centro de excelência na oferta do ensino de ciências, em geral, e de ciências aplicadas, em particular e qualificar-se como referência no apoio à oferta do ensino de ciências nas instituições públicas de ensino, oferecendo capacitação técnica e atualização aos docentes (OTRANTO, 2010, p. 101).

Dentre as finalidades e características dos IFs previsto na Lei № 11.892/2008, há o enfoque para a oferta da Pós-Graduação stricto sensu em seu art. 60, incisos I e II:

I - ofertar educação profissional e tecnológica, em todos os seus níveis e modalidades, formando e qualificando cidadãos com vistas na atuação profissional nos diversos setores da economia, com ênfase no desenvolvimento socioeconômico local, regional e nacional; II - desenvolver a educação profissional e tecnológica como processo educativo e investigativo de geração e adaptação de soluções técnicas e tecnológicas às demandas sociais e peculiaridades regionais (BRASIL, 2008).

O artigo 7으, onde a Lei trata dos objetivos dos IFs, percebe-se que a temática oferta de cursos em todos os níveis e modalidades é enfatizada novamente, quando faz referência ao objetivo de ministrar cursos de formação inicial e continuada de trabalhadores, objetivando a capacitação, o aperfeiçoamento, a especialização e a atualização de profissionais, em todos os níveis de escolaridade, nas áreas da educação profissional e tecnológica.

Ainda em seu artigo 7ำ, inciso IV, alínea e, traz como um dos objetivos dos Ifs: ministrar em nível de educação superior: e) cursos de Pós-Graduação stricto sensu de mestrado e doutorado, que contribuam para promover o estabelecimento de bases sólidas em educação, ciência e tecnologia, com vistas no processo de geração e inovação tecnológica.

As Instituições de Educação Profissional e Tecnológica buscam encontrar o seu espaço e se configurar como um eixo de formação que articula ofertas de ensino que vão do Ensino Básico à Pós-Graduação, considerando itinerários de formação de estudantes dentro de perfis de competências que as instituições governamentais, empresariais e associativas requerem. 
De acordo com Alves e Del Pino (2015), a criação dos IFs impactou na oferta de cursos de Pós-Graduação stricto sensu pelas instituições de Ensino Profissional. Houve um aumento de 186\% do número de Ifs, que passaram a ofertar cursos de Pós-Graduação stricto sensu e um crescimento de $414 \%$ de cursos oferecidos nos IFs no período de 2008 a 2014.

Comparando o crescimento dos cursos de Pós-Graduação stricto sensu ofertados pelos IFs e o crescimento da oferta de cursos de Pós-Graduação no país, verifica-se que o crescimento dos cursos nos IFs é muito maior. Enquanto a quantidade de cursos recomendados pela CAPES cresceu $46 \%$ entre 2008 e 2014, passando de 3893 cursos em 2008 para 5690 em 2014, nos IFs este crescimento foi de $414 \%$ no mesmo período. (Alves e Del Pino, 2015. p. 393).

Atualmente os IFs aparecem como instituições que abrangem a verticalização do ensino, com a oferta de cursos desde a Educação Básica até a Pós-Graduação stricto sensu, e os dispositivos legais deixam clara a importância da atuação desses Institutos no SNPG por meio da oferta de cursos de Pós-Graduação stricto sensu. De acordo com Pacheco (2010), o principal objetivo dos IFs é a profissionalização. O foco deve ser a formação para o exercício profissional tanto para os trabalhadores que necessitam para a realização de suas atividades profissionais de formação em nível superior, como para os que precisam da formação em nível médio técnico, e também para aqueles que atuam em qualificações profissionais mais especializadas; ao mesmo tempo, as atividades de pesquisa e extensão estão diretamente relacionadas ao mundo do trabalho.

Mesmo dotados de autonomia pedagógica e de gestão, e com o objetivo de ofertar cursos em todos os níveis da educação profissional e tecnológica, o papel dos IFs no SNPG ainda gera discussão por parte da comunidade científica e do governo (CAPES/MEC). Este fato deu origem ao Manifesto dos reitores dos Institutos Federais aprovado na 35a Reunião Ordinária do Conselho Nacional das Instituições da Rede Federal de Educação Profissional, Científica e Tecnológica (CONIF), realizada de 6 a 8 de agosto de 2013, em Natal (RN) e posteriormente ao seminário intitulado "A Rede Federal de Educação Profissional, Científica e Tecnológica no 
Sistema Nacional de Pós-Graduação", realizado em 19 de maio de 2014, em Brasília, cujo tema em destaque foi a importância do fortalecimento das políticas voltadas para o trabalho das instituições da Rede Federal na oferta da Pós-Graduação e do papel da CAPES neste contexto.

O manifesto da 35a Reunião Ordinária do CONIF deixa clara uma tensão de visão sobre a atuação das Universidades e dos IFs na Pós-Graduação stricto sensu. Esta tensão reflete a necessidade da comunidade acadêmica em separar as instituições de educação básica e profissional das instituições de educação superior, especificamente de Pós-Graduação stricto sensu, mesmo os dispositivos legais afirmando a verticalização da atuação dos IFs.

Antes de sua denominação como Instituto, os IFs já atuavam no SNPG buscando ofertar cursos de Pós-Graduação stricto sensu e com a lei 11.892/2008, que traz explicitamente dentre os objetivos e finalidades dos Institutos a oferta da Pós-Graduação, verificou-se um aumento na oferta de Pós-Graduação stricto sensu pelos IFs.

Tendo em vista este crescimento, surgiu a necessidade de analisar a participação e o desempenho dos IFs no Sistema de Avaliação da Pós-Graduação implantado pela CAPES, tendo em vista o contexto de submissão de propostas de cursos novos, recomendação e reavaliação dos Programas de Pós-Graduação stricto sensu pela CAPES. 


\section{METODOLOGIA}

Segundo Lakatos e Marconi (2003), a metodologia é considerada como o conjunto das atividades sistemáticas e racionais que, com maior segurança e economia, permite alcançar o objetivo, traçando o caminho a ser seguido, detectando erros e auxiliando as decisões do cientista.

O presente estudo é caracterizado como pesquisa bibliográfica, que se deu por meio da análise das informações obtidas por revisão de literatura, e pesquisa documental que se deu pelo levantamentos de informações e dados que fazem parte do Sistema Nacional de PósGraduação e documentos disponibilizados pela Diretoria de Avaliação da CAPES e áreas de avaliação, como fichas de avaliação das propostas de cursos novos, fichas da avaliação Trienal, documentos das áreas de avaliação, como os requisitos de cursos novos.

De acordo com Vergara (2005), a pesquisa bibliográfica consiste em um estudo sistematizado desenvolvido em material publicado em livros, revistas, jornais e redes eletrônicas, isto é, material acessível ao público em geral; e a pesquisa documental é a realizada em documentos conservados no interior de órgãos públicos e privados de qualquer natureza, ou com pessoas registros canais, regulamentos, circulares, ofícios, memorandos, balancetes, comunicações informais, filmes, microfilmes, fotografias, videoteipe, informações em disquete, diários, cartas pessoais e outros.

Para analisar a participação e desempenho dos IFs no Sistema Nacional de Pós-Graduação, a metodologia adotada nesta pesquisa foi de natureza quantitativa, com base nos dados fornecidos pela Diretoria de Avaliação da CAPES.

O método quantitativo, como o próprio nome indica, caracteriza-se pelo emprego da quantificação tanto nas modalidades de coleta de informações, quanto no tratamento delas por meio de técnicas estatísticas, desde as mais simples como as mais complexas (RICHARDSON et al, 1999, p. 70).

A interpretação dos dados é basal na técnica da pesquisa quantitativa e serviu para análise 
dos dados sobre propostas e cursos de Pós-Graduação stricto sensu ofertados pelos IFs.

A coleta de dados se deu por meio do levantamento de informações sobre propostas de cursos novos de Pós-Graduação stricto sensu, submetidos pelos IFs à avaliação da CAPES no período de 2000 a 2013 e sobre os cursos ofertados pelos IFs recomendados pela CAPES. Os dados foram extraídos do SNPG, fornecidos pela Diretoria de Avaliação - DAV da CAPES. O estudo foi composto pelas 143 propostas de cursos novos e pelos 36 cursos de PósGraduação stricto sensu, oferecidos pelos 20 IFs e recomendados pela CAPES até a Avaliação de Propostas de Cursos Novos - APCN 2013 que teve sua análise concluída em agosto de 2014. 


\section{RESULTADOS E DISCUSSÃO}

Constatado o crescimento da Pós-Graduação stricto sensu nos IFs e analisando uma das finalidades dos IFs que é a oferta de cursos de Pós-Graduação stricto sensu, surge a questão de como está sendo a participação e desempenho dessas instituições no contexto do Sistema de Avaliação da Pós-Graduação.

Durante o período de 2000 a 2013, os IFs submeteram à avaliação da CAPES 143 propostas de cursos novos de Pós-Graduação stricto sensu. Conforme pode ser observado na Figura 2, constatou-se que a partir de 2010 houve um aumento da submissão de propostas de cursos novos, que pode estar relacionado com um dos objetivos dos IFs expresso na Lei 11.892/2008 que é a oferta de cursos de Pós-Graduação stricto sensu pelos Institutos Federais.

Figura 2. Propostas de cursos novos de Pós-Graduação stricto sensu submetidas à avaliação da CAPES pelos IFs no período 2000 à 2013.

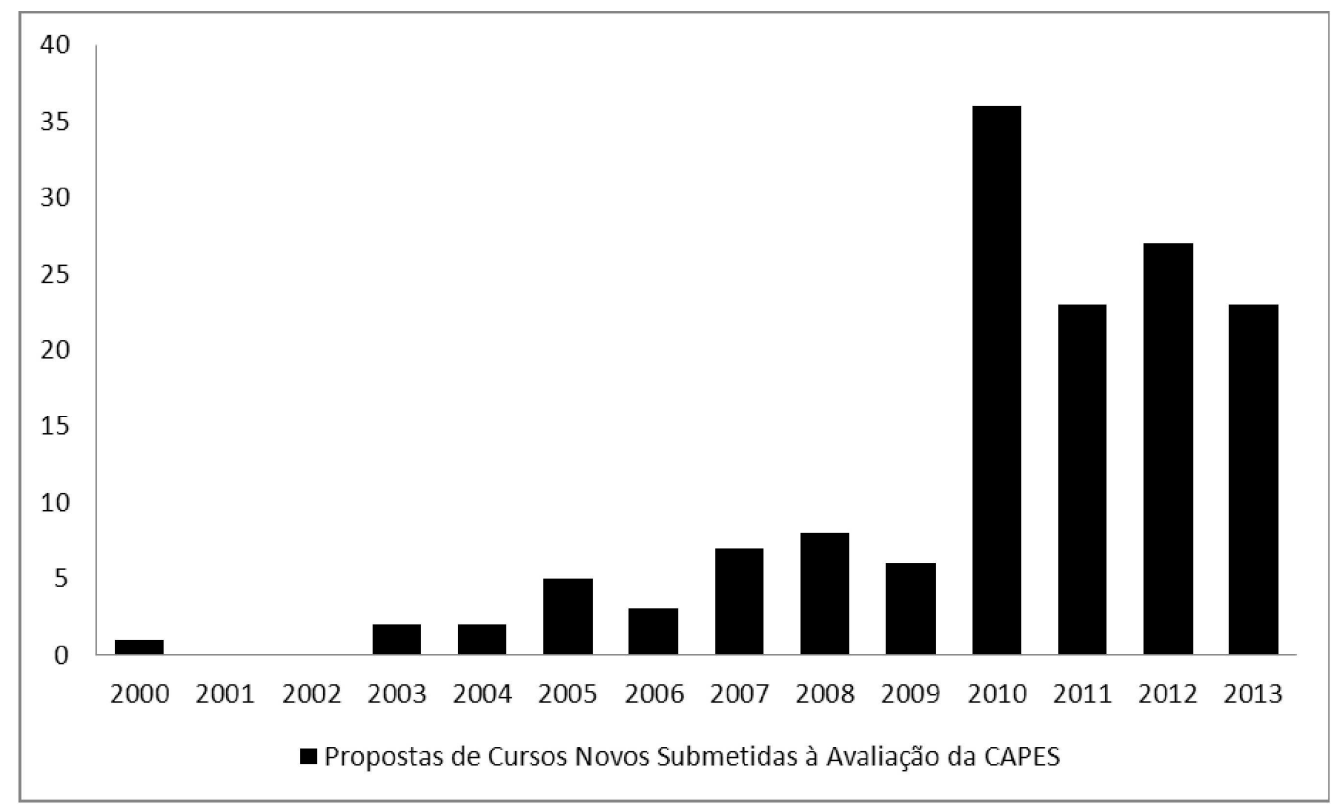

Fonte: SNPG/DAV/CAPES.

Este aumento na submissão foi tanto nas propostas de modalidade acadêmica como profissional. No entanto, apesar dos dispositivos legais enfatizarem como finalidade dos IFs a 
oferta de educação profissional e tecnológica em todos os níveis, a modalidade de cursos de Pós-Graduação stricto sensu acadêmica (mestrados acadêmicos e doutorado) concentra maior parte das propostas submetidas pelos Institutos no período de 2000 a 2013, conforme pode ser observado na Figura 3. Das 143 propostas submetidas por IFs 78 são acadêmicas ( 75 mestrados acadêmicos e 3 doutorados) e 65 são profissionais.

Figura 3. Submissão de Propostas de Cursos Novos submetidos pelos IFs distribuídos por modalidade (Acadêmicas e Profissionais) - Período 2000 a 2013.

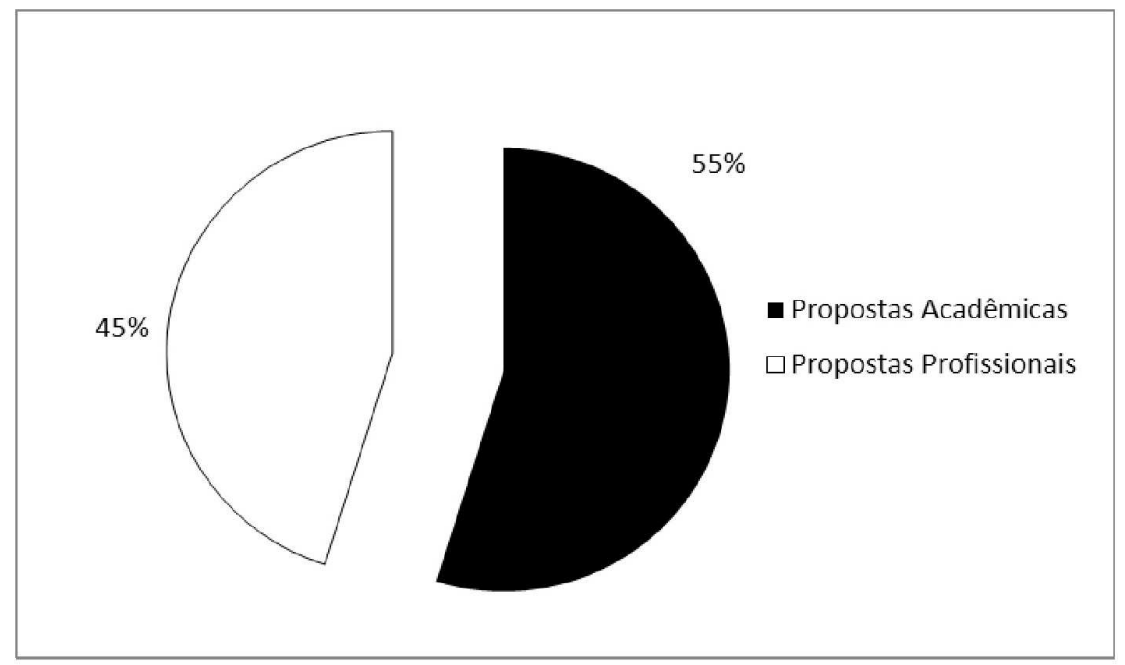

Fonte: SNPG/DAV/CAPES.

A maior submissão na modalidade acadêmica reflete uma valorização maior da PósGraduação acadêmica em detrimento da profissional, mesmo em instituições que fazem parte da Rede Federal de Educação Profissional, Científica e Tecnológica. Este fato pode estar relacionado com a limitação de concessão de bolsas de estudos na modalidade profissional prevista no art. 11 da Portaria MEC no 17/2009.

No entanto, cabe destacar que este predomínio na submissão em propostas acadêmicas não reflete na quantidade de cursos recomendados pela CAPES para oferta nos Institutos. Até o presente estudo, 53\% dos cursos de Pós-Graduação stricto sensu ofertados pelos IFs pertenciam à modalidade profissional, conforme Figura 4. 
Figura 4. Comparação entre as modalidades (Acadêmicos e Profissionais) dos cursos de Pós-Graduação stricto sensu oferecidas pelos IFs no período 2000 a 2014.

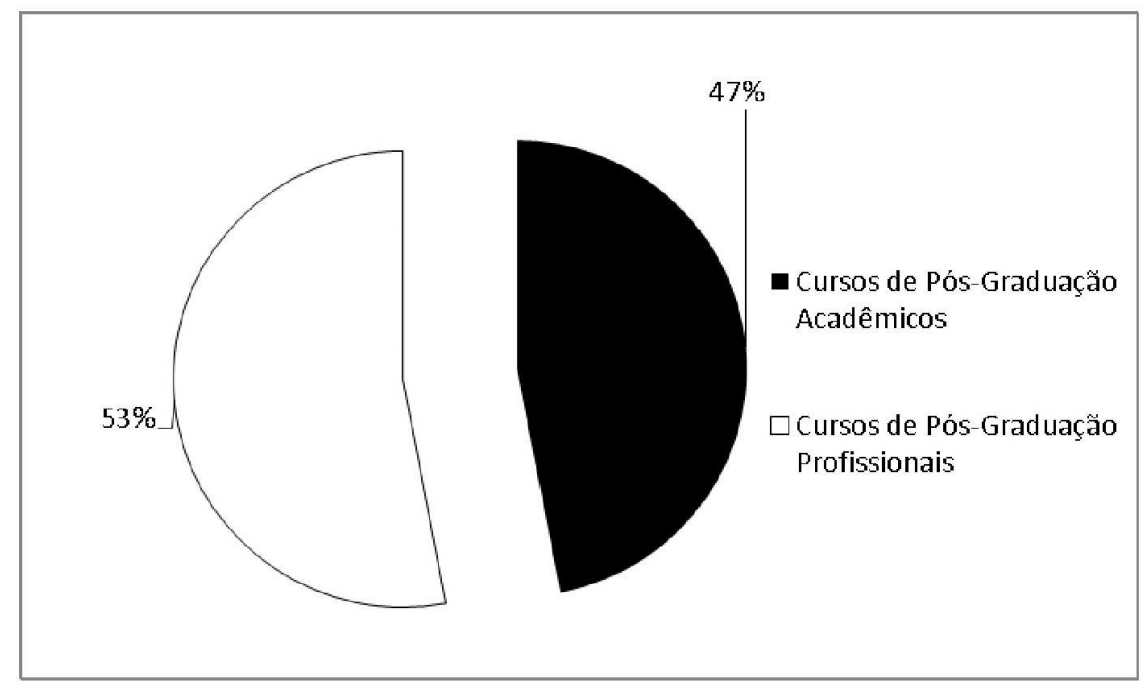

Fonte: SNPG/DAV/CAPES.

Com relação às áreas de avaliação em que as propostas de cursos novos são submetidas, as áreas de Interdisciplinar e Ciências Agrárias são as que mais recebem propostas (Tabela 1).

Tabela 1. Distribuição das propostas de cursos novos submetidas à avaliação da CAPES pelos IFs por área de avaliação - período 2000 a 2013.

\begin{tabular}{|l|c|}
\hline \multicolumn{1}{|c|}{ Áreas de Avaliação } & $\begin{array}{c}\text { Propostas } \\
\text { Submetidas }\end{array}$ \\
\hline Interdisciplinar & 27 \\
\hline Ciências Agrárias & 26 \\
\hline Engenharias IV & 15 \\
\hline Engenharias III & 12 \\
\hline Educação & 11 \\
\hline Engenharias II & 10 \\
\hline Ensino & 9 \\
\hline Ciências de Alimentos & 7 \\
\hline Engenharias I & 6 \\
\hline Química & 6 \\
\hline Zootecnia & 4 \\
\hline Biodiversidade & 2 \\
\hline Ciências Ambientais & 2 \\
\hline
\end{tabular}




\begin{tabular}{|l|c|}
\hline Ciências da Computação & 2 \\
\hline Astronomia/Física & 1 \\
\hline Biotecnologia & 1 \\
\hline Ciências Biológicas I & 1 \\
\hline Educação Física & 1 \\
\hline Total & 143 \\
\hline
\end{tabular}

Fonte: SNPG/DAV/CAPES.

Ciências Agrárias se destaca como uma das áreas com maior número de propostas de cursos novos se deve à transformação das Escolas Agrotécnicas Federais em IFs, indicando uma das vocações desses Institutos. No entanto, a área com maior número de propostas submetidas não reflete na área com maior número de cursos recomendados. Atualmente Ensino é a área com maior número de cursos de Pós-Graduação recomendados pela CAPES (Tabela 2).

Tabela 2. Distribuição dos cursos de Pós-Graduação stricto sensu oferecidos pelos IFs por área de avaliação no ano de 2014.

\begin{tabular}{|l|c|c|c|}
\hline \multicolumn{1}{|c|}{ Áreas de Avaliação } & $\begin{array}{c}\text { Cursos } \\
\text { Acadêmicos }\end{array}$ & $\begin{array}{c}\text { Cursos } \\
\text { Profissionais }\end{array}$ & No de Cursos \\
\hline Ensino & 1 & 6 & 7 \\
\hline Ciências de Alimentos & 2 & 3 & 5 \\
\hline Ciências Agrárias & 3 & 1 & 4 \\
\hline Engenharias II & 3 & 2 & 3 \\
\hline Engenharias III & 1 & 2 & 3 \\
\hline Interdisciplinar & 1 & 2 & 3 \\
\hline Educação & 1 & 1 & 3 \\
\hline Engenharias I & 1 & 0 & 2 \\
\hline Engenharias IV & 2 & 2 & 2 \\
\hline Ciências Ambientais & 0 & 0 & 1 \\
\hline Zootecnia/Recursos Pesqueiros & 1 & 0 & 1 \\
\hline Ciências da Computação & 1 & 19 & 36 \\
\hline Total & 17 & 2 & 2 \\
\hline
\end{tabular}

Fonte: SNPG/DAV/CAPES.

A discrepância entre o número de propostas submetidas e o número de cursos 
recomendados pela CAPES leva a análise sobre o índice de recomendação destas propostas submetidas pelos IFs. No período de 2000 a 2013, o índice de recomendação das propostas de cursos novos de Pós-Graduação stricto sensu submetidos por IFs foi de $25 \%$. Este índice de recomendação se mostra mais baixo comparando-o com o índice de recomendação de todas as propostas submetidas à avaliação da CAPES no período de 2000 a 2013 , que é de $51 \%$ de recomendação, conforme Figura 5.

Figura 5. Comparação entre os índices de recomendação das propostas de cursos novos submetidas à Avaliação da CAPES no período de 2000 a 2013 pelos IFs e por todas as Instituições.

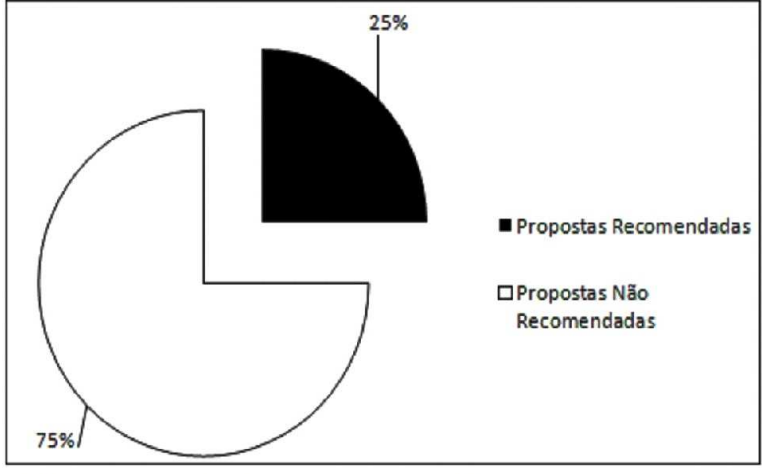

a) Propostas Submetidas por IFs

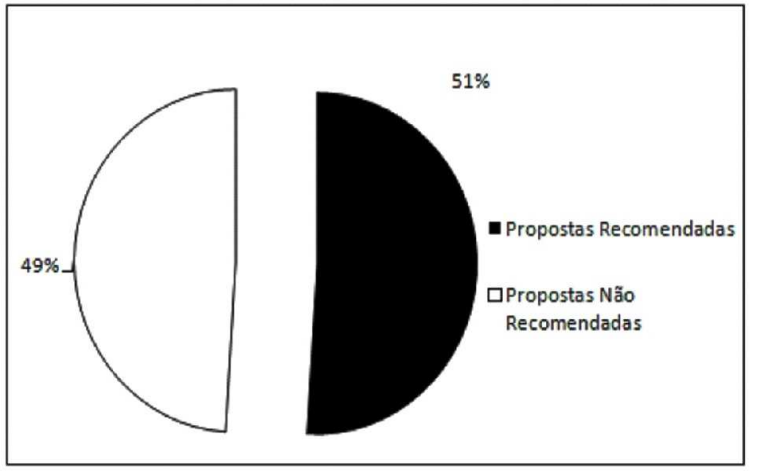

b) Propostas Submetidas por todas as Instituições

Fonte: SNPG/DAV/CAPES.

No período de 2000 a 2013 foram submetidas 7113 propostas de cursos novos de PósGraduação à avaliação da CAPES. Os IFs submeteram 143 propostas. Chama a atenção o aumento de submissões a partir de 2010 tanto pelos IFs quanto pelas outras instituições; no entanto, no caso dos IFs este aumento na submissão não reflete proporcionalmente o número de cursos recomendados pela CAPES, conforme pode ser observado nas figuras 6 e 7. 
Figura 6. Comparação entre propostas de cursos novos submetidas à avaliação da CAPES pelos IFs e propostas recomendadas no período 2000 a 2013.

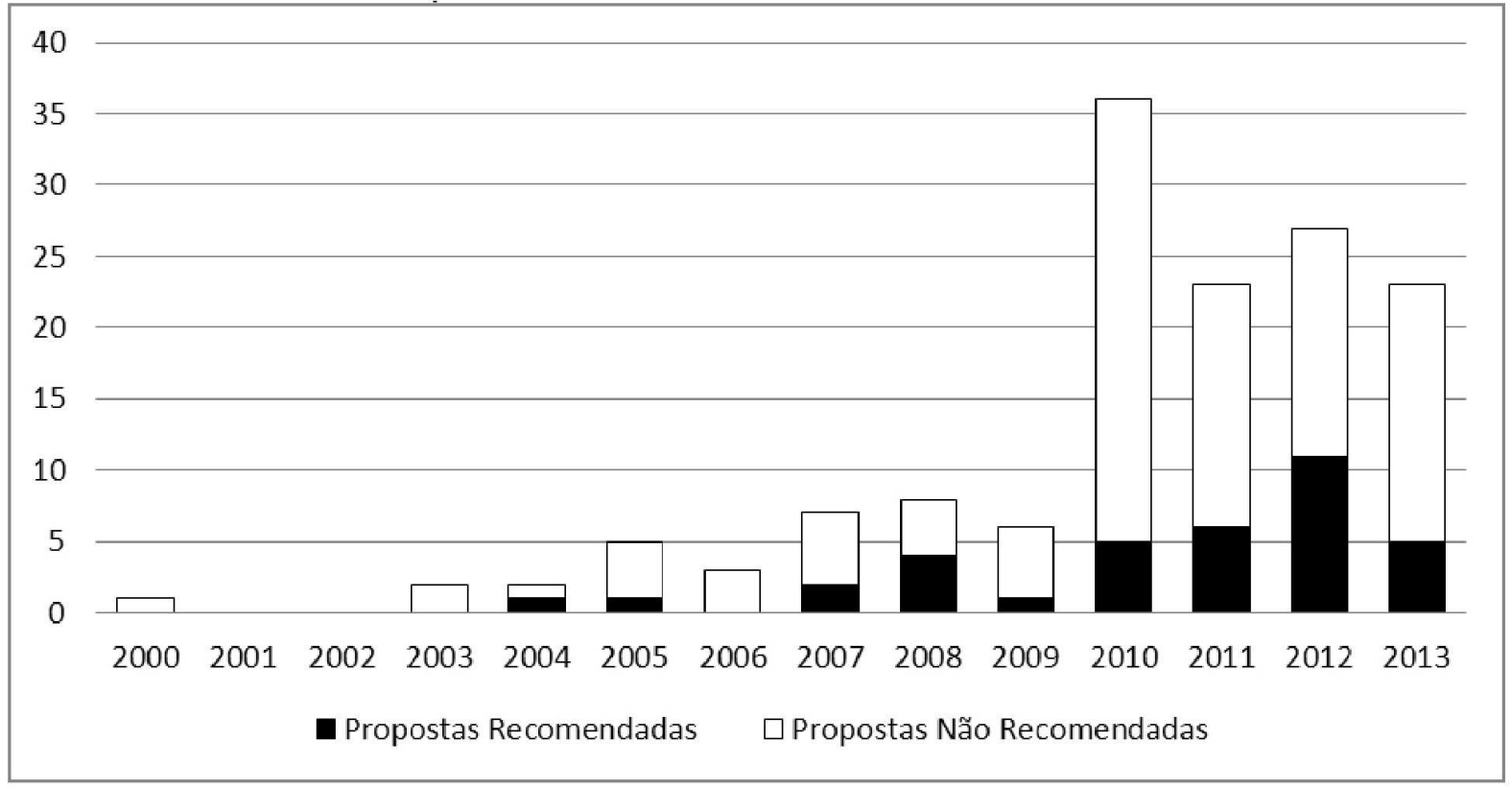

Fonte: SNPG/DAV/CAPES.

Figura 7. Comparação de todas as propostas de cursos novos submetidas à avaliação da CAPES por todas as Instituições e propostas recomendadas no período 2000 a 2013.

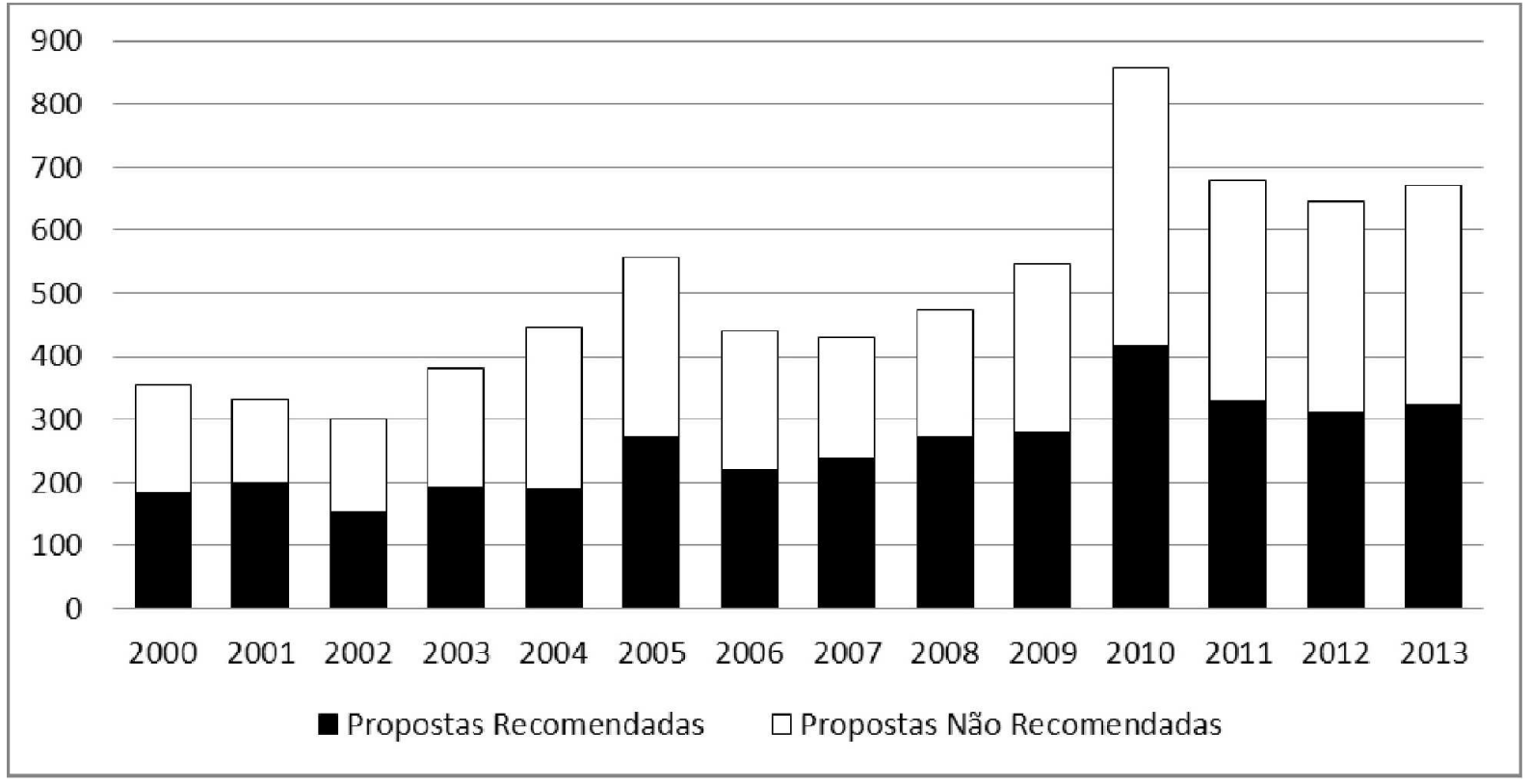

Fonte: SNPG/DAV/CAPES.

No caso dos IFs, não houve aumento nos índices de recomendação e mesmo com muitas 
propostas submetidas ao longo dos anos, o número de propostas não recomendadas também se mostra elevado. Nas Figuras 8 e 9, pode-se observar a comparação da evolução do índice de recomendação das propostas de cursos novos submetidas à avaliação da CAPES pelos IFs e do total de propostas submetidas por todas as instituições no período de 2000 a 2013.

Figura 8. Evolução do Índice de recomendação das propostas de cursos novos submetidas à avaliação da CAPES pelos IFs no período 2000 à 2013.

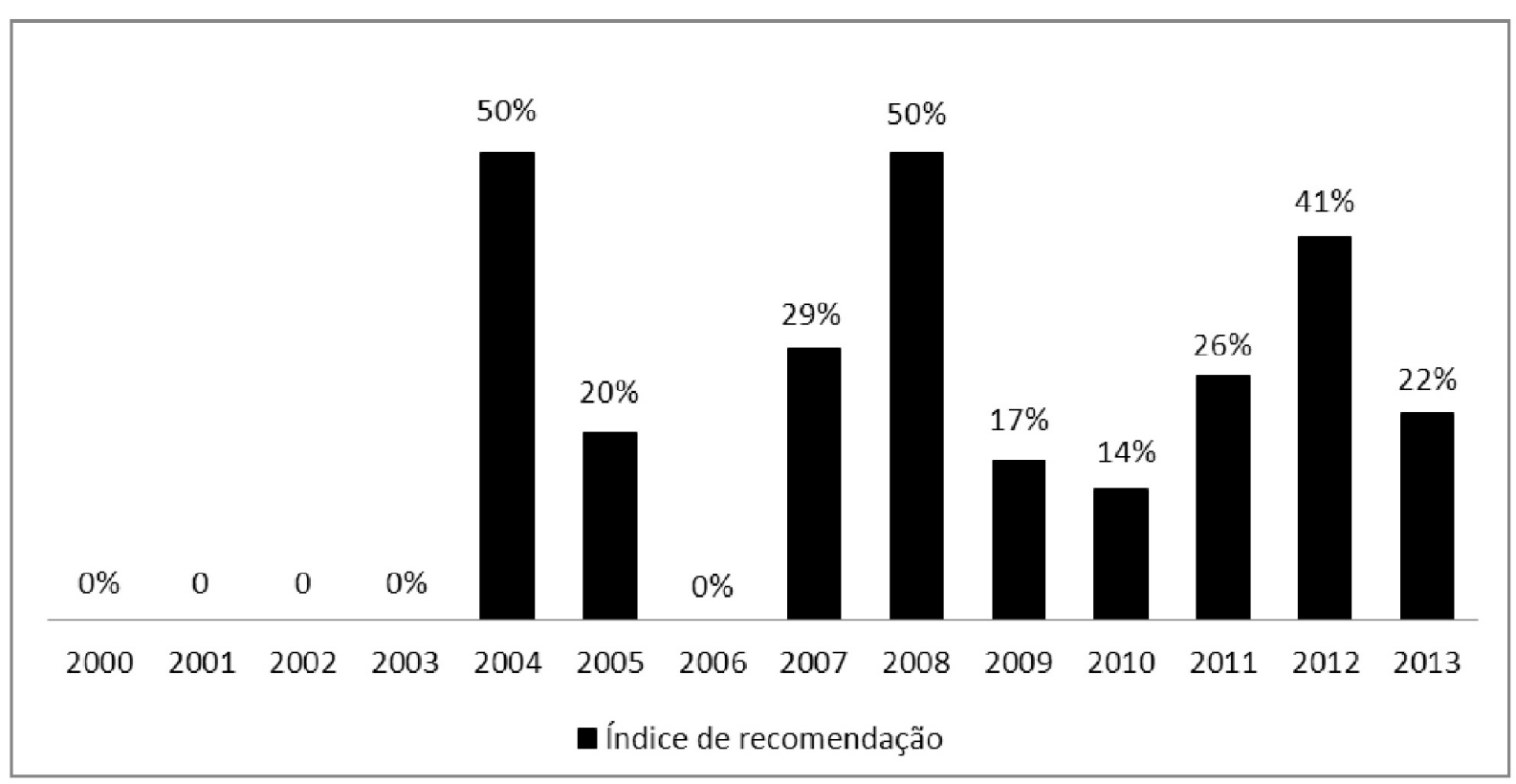

Fonte: SNPG/DAV/CAPES. 
Figura 9. Evolução do Índice de recomendação de propostas de cursos novos submetidas à avaliação da CAPES por todas as Instituições no período 2000 à 2013.

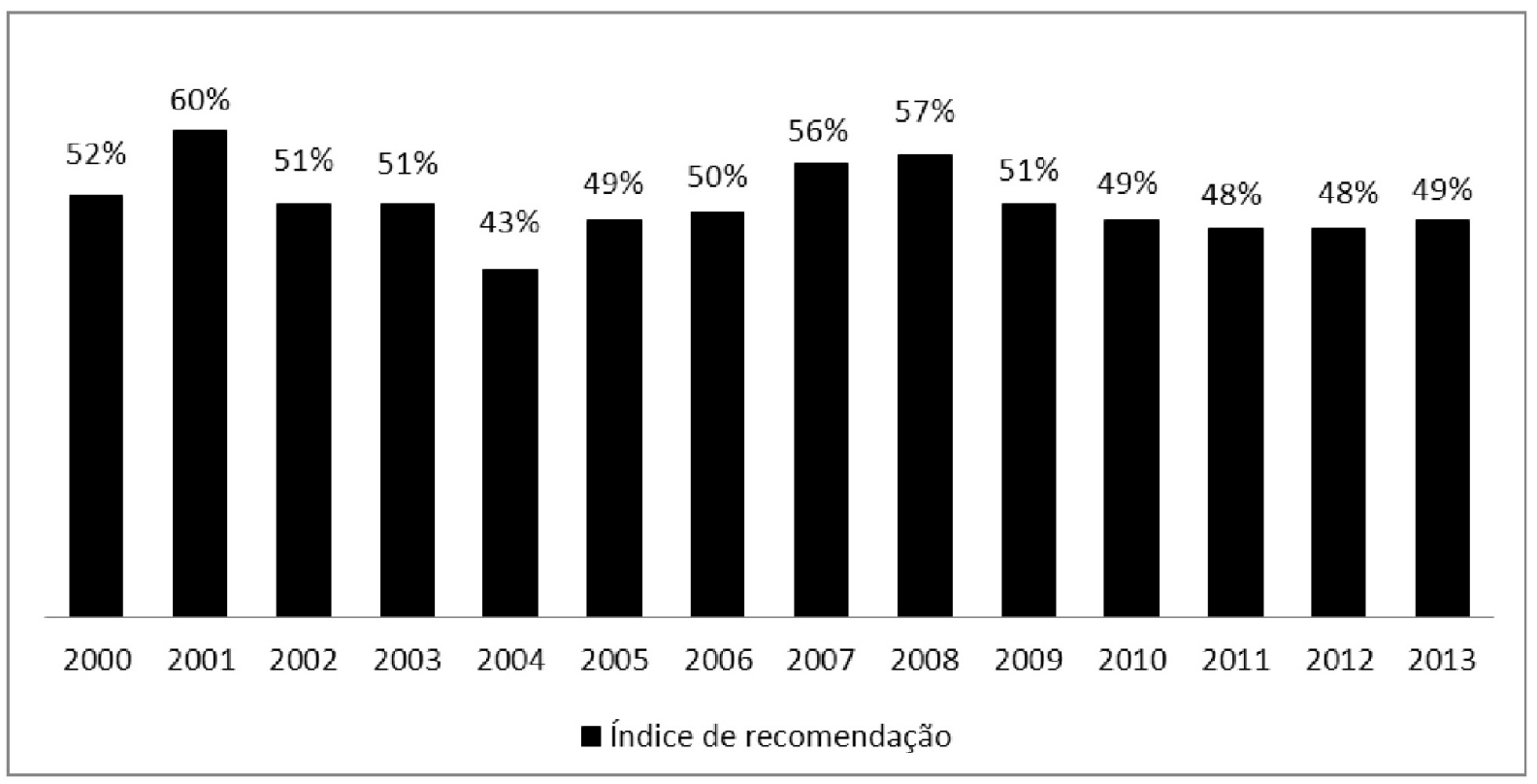

Fonte: SNPG/DAV/CAPES.

Comparando os índices de recomendação das propostas por modalidades, a modalidade profissional tem maior índice de recomendação (Figura 10), explicando o fato de, mesmo os IFs submetendo mais propostas acadêmicas, a oferta ser maior na modalidade profissional.

Figura 10. Comparação entre os índices de recomendação das propostas de cursos novos submetidas à

Avaliação da CAPES pelos IFs no período 2000 a 2013 nas modalidades acadêmicas e profissionais.

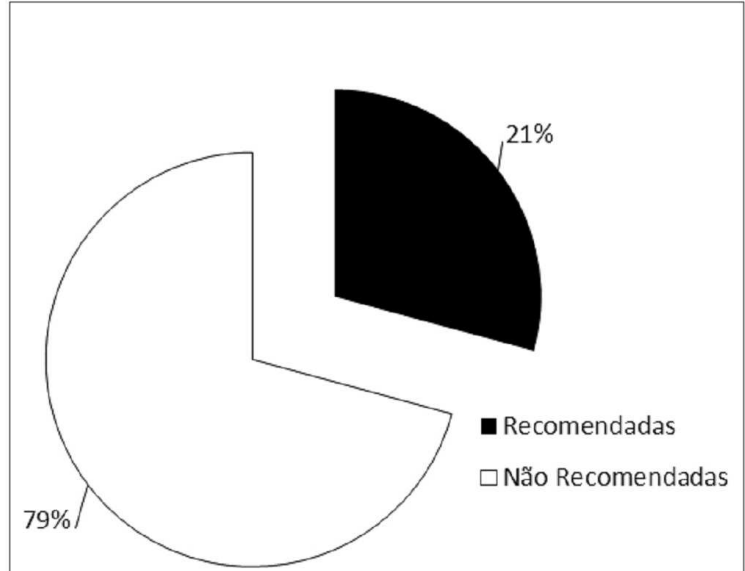

a) Modalidade Acadêmica

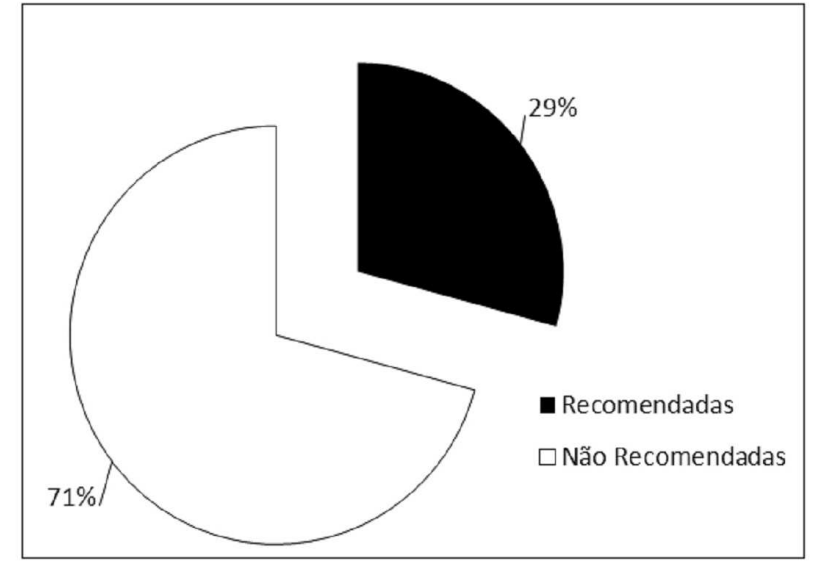

b) Modalidade Profissional

Fonte: SNPG/DAV/CAPES. 
Os índices de recomendação das propostas refletem também a discrepância entre as áreas de avaliação que recebem o maior número de propostas, que são as áreas Interdisciplinar e Ciências Agrárias, e a Área de Avaliação que possui maior número de cursos de PósGraduação stricto sensu recomendados pela CAPES, que é a área de Ensino. Conforme pode ser observado na Tabela 3, a área de Ensino possui um alto índice de recomendação, 77,5\%. De 2000 a 2013 foram submetidas 9 propostas e 7 foram recomendadas pela CAPES.

Tabela 3. Comparação dos índices de aprovação das propostas de cursos submetidas à avaliação da CAPES pelos IFs por área de avaliação no período de 2000 a 2013.

\begin{tabular}{|c|c|c|c|}
\hline Áreas de Avaliação & $\begin{array}{l}\text { Propostas } \\
\text { Submetidas }\end{array}$ & $\begin{array}{c}\text { Propostas } \\
\text { Recomendadas }\end{array}$ & $\begin{array}{c}\text { Índice de } \\
\text { recomendação }\end{array}$ \\
\hline Interdisciplinar & 27 & 3 & $11 \%$ \\
\hline Ciências Agrárias & 26 & 4 & $15 \%$ \\
\hline Engenharias IV & 15 & 2 & $13 \%$ \\
\hline Engenharias III & 12 & 3 & $25 \%$ \\
\hline Educação & 11 & 3 & $27 \%$ \\
\hline Engenharias II & 10 & 3 & $30 \%$ \\
\hline Ensino & 9 & 7 & $77,5 \%$ \\
\hline Ciências de Alimentos & 7 & 5 & $71 \%$ \\
\hline Engenharias I & 6 & 2 & $33 \%$ \\
\hline Química & 6 & 0 & $0 \%$ \\
\hline Zootecnia & 4 & 1 & $25 \%$ \\
\hline Biodiversidade & 2 & 0 & $0 \%$ \\
\hline Ciências Ambientais & 2 & 2 & $100 \%$ \\
\hline Ciências da Computação & 2 & 1 & $50 \%$ \\
\hline Astronomia/Física & 1 & 0 & $0 \%$ \\
\hline Biotecnologia & 1 & 0 & $0 \%$ \\
\hline Ciências Biológicas I & 1 & 0 & $0 \%$ \\
\hline Educação Física & 1 & 0 & $0 \%$ \\
\hline Total & 143 & 36 & $25 \%$ \\
\hline
\end{tabular}

Fonte: SNPG/DAV/CAPES.

Os dados indicam que independente do número de propostas submetidas, o número de cursos de Pós-Graduação stricto sensu não aumentou proporcionalmente ao número de 
submissões. A verificação dos baixos índices de recomendação das propostas de cursos novos chama a atenção para análise das fragilidades destas propostas.

A avaliação das propostas de cursos novos é realizada em primeira instância pelas Comissões de Área e em segunda instância pelo CTC-ES e registrada em fichas de avaliação estruturadas em quesitos (avaliados como sim ou não) abordando: Quesito 1: Comprometimento da Instituição; Quesito 2: Infraestrutura; Quesito 3: Proposta do curso; Quesito 4: Dimensão e regime de trabalho do corpo docente; e Quesito 5: Produtividade docente e consolidação da capacidade de pesquisa. A nota atribuída às propostas varia de 1 a 7 , sendo nota igual ou superior a 3 o curso será recomendado.

$\mathrm{Na}$ análise dos quesitos avaliados das 143 propostas de cursos novos submetidas entre 2000 e 2013, o quesito mais avaliado negativamente foi o quesito 5, conforme pode ser observado na Figura 11. O quesito em questão trata sobre a produtividade docente e consolidação da capacidade de pesquisa, que foi avaliado positivamente em apenas $21 \%$ das propostas.

Figura 11. Avaliação dos quesitos da ficha de recomendação das propostas de cursos novos submetidas à avaliação da CAPES pelos IFs - período 2000 à 2013.

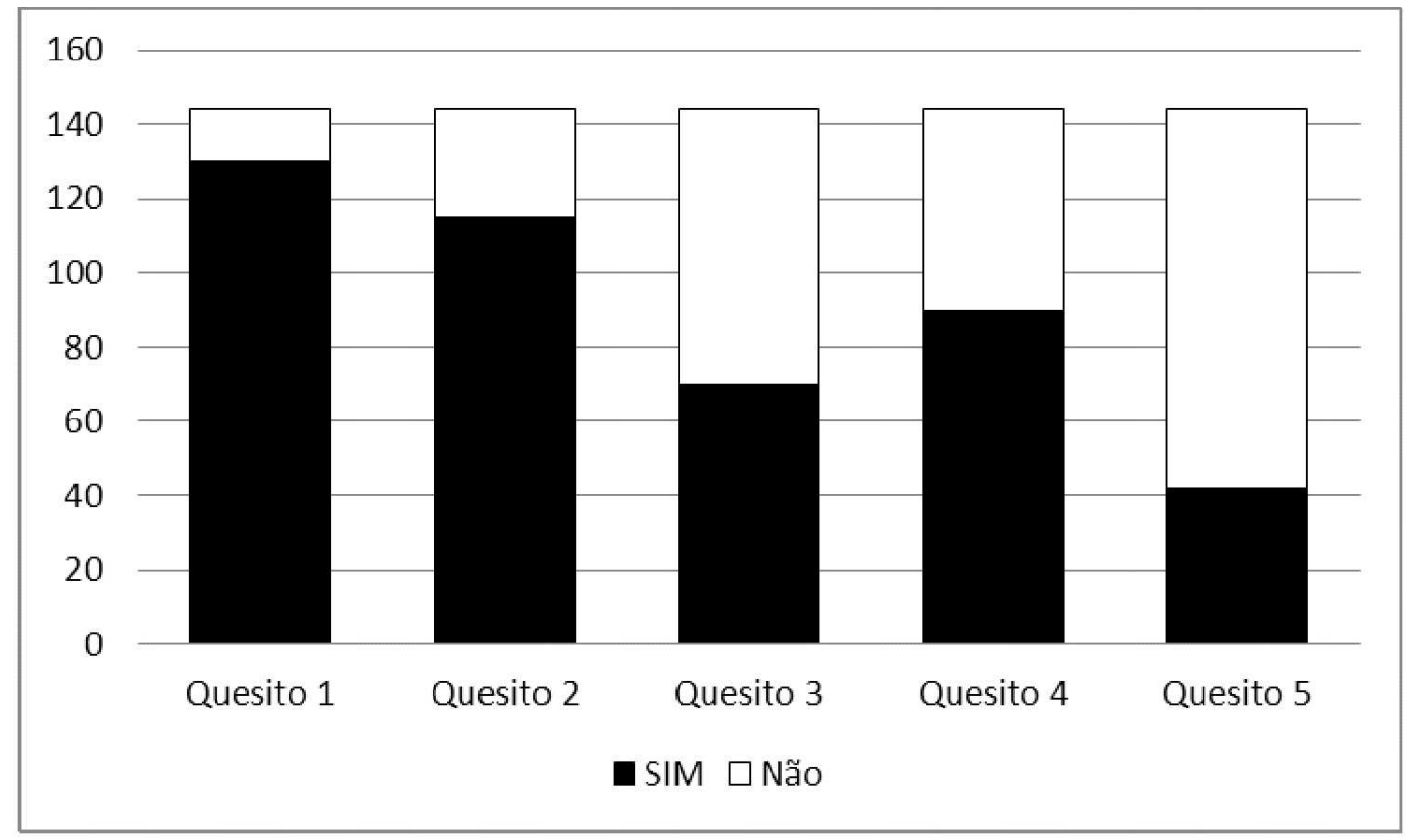

Fonte: SNPG/DAV/CAPES. 
Cabe destacar que o quesito 3, referente a proposta do programa, também foi avaliado negativamente em maior parte das propostas (recebeu "sim" em somente $48 \%$ das propostas).

Por outro lado, os quesitos 1 e 2 , que tratam sobre o comprometimento institucional e infraestrutura foram os mais bem avaliados, recebendo avaliação positiva respectivamente em $90 \%$ e $80 \%$ das propostas avaliadas.

O quesito 4, que trata sobre a dimensão do corpo docente, foi avaliado positivamente em $62 \%$ das propostas e não se configurou como uma importante fragilidade das propostas.

Esses dados revelam que a maior fragilidade das propostas de cursos novos de PósGraduação stricto sensu está na produtividade docente e consolidação da capacidade de pesquisa. Mesmo atendendo aos requisitos de comprometimento institucional, infraestrutura e dimensão do corpo docente, é necessário envidar esforços para fortalecer a produtividade docente e consolidação da capacidade de pesquisa. Algumas das exigências previstas nos requisitos de cursos novos das áreas de avaliação é que a produção do corpo docente, principalmente do corpo docente permanente, esteja relacionada com a proposta do programa, área de concentração e linhas de pesquisa, apresente produção científica em periódicos indexados e que estão classificados nos estratos superiores do Qualis das Áreas de Avaliação (A1, A2, B1 e B2), publicação em livros, experiência na aprovação e execução de projetos de pesquisa, experiência em orientação, produção tecnológica, dentre outras exigências especificadas nos requisitos de cursos novos das 48 áreas de avaliação, disponíveis na página da CAPES.

Do total de 143 propostas de cursos novos submetidas à avaliação da CAPES pelos IFs no período de 2000 a 2013, 36 propostas foram recomendadas. A primeira proposta foi recomendada pela CAPES em 2004. 
A partir da recomendação pela CAPES, o curso de Pós-Graduação stricto sensu passa a fazer parte do SNPG e, até 2013, era reavaliado a cada triênio. Em dezembro de 2014, o Conselho Superior da CAPES, em sua 68a reunião, decidiu que a reavaliação dos cursos de PósGraduação stricto sensu do SNPG passaria a ser quadrienal, conforme Resolução do Conselho Superior da CAPES no 05, de 11 de dezembro de 2014.

Após a recomendação do curso pela CAPES, uma análise importante é verificar como foi o desempenho dos Programas de Pós-Graduação, ofertados pelos IFs nas avaliações trienais que aconteceram nos anos de 2007, 2010 e 2013, referentes aos respectivos períodos: 2004 a 2006, 2007 a 2009 e 2010 a 2012.

Dos 36 cursos de Pós-Graduação stricto sensu ofertados por IFs, 19 cursos já foram reavaliados nas Avaliações Trienais. Os outros 17 cursos ainda não foram reavaliados porque iniciaram atividades letivas a partir do ano de 2013 e entrarão na clientela da próxima avaliação que acontecerá em 2017. Analisando o desempenho dos cursos reavaliados pela CAPES, 2 cursos aumentaram o desempenho subindo de nota 3 para 4 na trienal de 2013,17 cursos mantiveram nota 3 e nenhum curso foi descredenciado. Este dado revela que, após recomendado pela CAPES, os Programas de Pós-Graduação stricto sensu ofertados pelos IFs têm mantido ou aumentado os seus desempenhos.

O bom desempenho dos programas ofertados pelos IFs nas reavaliações da CAPES confirma a qualidade dessas instituições na atuação na Pós-Graduação stricto sensu. 


\section{CONSIDERAÇÕES FINAIS}

Atualmente os IFs atuam em todo território nacional tendo como objetivos a formação de recursos humanos e produção do conhecimento, da oferta de educação superior, básica e profissional, especializados na oferta de educação profissional e tecnológica nas diferentes modalidades de ensino, incluindo a Pós-Graduação stricto sensu.

Analisando as finalidades, características e objetivos dos IFs, verificou-se por meio deste estudo que após a criação dos Institutos Federais, pela Lei no 11.892/2008, houve uma maior participação dos IFs no Sistema de Avaliação da Pós-Graduação por meio do aumento da submissão de propostas de cursos novos de Pós-Graduação stricto sensu, embora maior parte das propostas submetidas (75\%) não tenha obtido desempenho satisfatório, que é a recomendação do curso pela CAPES.

O estudo revelou que a procura dos IFs é maior por cursos de Pós-Graduação stricto sensu na modalidade acadêmica, no entanto o índice de recomendação pela CAPES é maior na modalidade profissional, fazendo com que a maioria dos cursos de Pós-Graduação stricto sensu recomendados pela CAPES, ofertados por IFs, sejam na modalidade profissionais. Com relação à submissão por área de avaliação, as áreas Interdisciplinar e Ciências Agrárias são as mais procuradas, mas é na área de Ensino que as propostas apresentam alto índice de recomendação, destacando-se como a Área de Avaliação que concentra maior parte dos cursos de Pós-Graduação ofertados por IFs.

Analisando os índices de recomendação, foi possível verificar as fragilidades apresentadas nas propostas que levam a não recomendação pela CAPES. Cabe destacar que a principal fragilidade encontrada se refere à produtividade docente e capacidade de consolidação de pesquisa. Isso indica que os Institutos, mesmo atendendo outros requisitos para oferta de um curso de Pós-Graduação stricto sensu como comprometimento institucional e infraestrutura, precisam fortalecer o seu corpo docente em termos de produtividade e desenvolvimento de pesquisa. 
Já o desempenho dos cursos de Pós-Graduação ofertado nos IFs nas avaliações trienais 2007, 2010 e 2013 se mostrou satisfatório tendo em vista que, desde a primeira recomendação, nenhum curso foi descredenciado nas reavaliações realizadas pela CAPES e 2 cursos aumentaram a nota de 3 para 4.

Pelo exposto, percebe-se que a atuação dos Institutos Federais de Educação, Ciência e Tecnologia no Sistema Nacional de Pós-Graduação vem aumentando ao longo dos anos. Embora o índice de recomendação das propostas, que é de $25 \%$, não seja alto, o empenho em fazer uma proposta de curso de Pós-Graduação stricto sensu já mostra uma participação mais ativa no SNPG aumentando o reconhecimento dos IFs como instituições com competência para atuar em todos os níveis e modalidade de ensino. 


\section{REFERÊNCIAS}

ALMEIDA, M. H. T. A Pós-Graduação no Brasil: onde está e para onde poderia ir. In BRASIL. MEC. Coordenação de Aperfeiçoamento de Pessoal de Nível Superior. Plano Nacional de PósGraduação - PNPG, v. 2020, p. 17-28. 2011.

ALVES, C. G. M.; DEL PINO, J. C. A atuação dos IFs frente ao Sistema Nacional de PósGraduação - Um comparativo entre 2008-2014. HOLOS (Natal. Online) v. 5, p. 379-400, 2015.

BARROS, E. M. C. Política de Pós-Graduação: um estudo da participação da comunidade científica. São Paulo: Editora UFSCar, 1998.

BRASIL. Decreto no 7.566, de 23 de setembro de 1909. Crêa nas capitaes dos Estados da Republica Escolas de Aprendizes Artifices, para o ensino profissional primario e gratuito. Rio de Janeiro, 1909. Disponível em: <http://www6.senado.gov.br/legislacao/ListaNorma. action?numero=7566\&tipo_norma=DEC\&data=19090923\&link=s $>$. Acesso em: 3 fev. 2014.

BRASIL. Constituição dos Estados Unidos do Brasil, de 10 de novembro de 1937. Disponível em: <planalto.gov.br/ccivil_03/Constituicao/Constitui\%C3\%A7ao37.htm>. Acesso em: 5 fev. 2014.

BRASIL. MEC/CFE. Parecer CFE n.o 977, de 3 de dezembro de 1965. Definição dos Cursos de Pós-Graduação, 1965a. Disponível em: <scielo.br/scielo.php?script=sci_arttext\&pid=S141324782005000300014>. Acesso em: 5 fev. 2014.

BRASIL. Decreto no 29.741, de 11 de Julho de 1951. Institui uma Comissão para promover a Campanha Nacional de Aperfeiçoamento de pessoal de nível superior. Rio de Janeiro, 1951. Disponível em: <www2.camara.leg.br/legin/fed/decret/1950-1959/decreto-29741-11-julho1951-336144-publicacaooriginal-1-pe.html>. Acesso em: 3 fev. 2014

BRASIL. Lei no 3.552, de 16 de fevereiro de 1959. Dispõe sobre nova organização escolar e administrativa dos estabelecimentos de ensino industrial do Ministério da Educação e Cultura, e dá outras providências. Rio de Janeiro, 1959. Disponível em: <planalto.gov.br/ccivil_03/Leis/L3552.htm>. Acesso em: 3 fev. 2014.

BRASIL. Lei no 8.948, de 8 de dezembro de 1994. Dispõe sobre a instituição do Sistema Nacional de Educação Tecnológica e dá outras providências., 1994. Disponível em: <planalto.gov.br/ccivil_03/leis/L8948.htm> Acesso em: 3 fev. 2014.

BRASIL. MEC/Conselho Nacional de Educação. Câmara de Educação Superior. Parecer CNE/CES n.o 79, de 12 de março de 2002. Consulta sobre titulação de programa de mestrado profissionalizante, $2002 . \quad$ Disponível em: <portal.mec.gov.br/cne/arquivos/pdf/2002/pces079_02.pdf>. Acesso em: 5 jun. 2014. 
BRASIL. Lei no 11.184, de 7 de outubro de 2005. Dispõe sobre a transformação do Centro Federal de Educação Tecnológica do Paraná em Universidade Tecnológica Federal do Paraná e dá outras providências. Brasília, 2005. Disponível em: <planalto.gov.br/ccivil_03/_Ato20042006/2005/Lei/L11184.htm>. Acesso em: 3 fev. 2014.

BRASIL. Decreto no 6.095, de 24 de abril de 2007. Estabelece diretrizes para o processo de integração de instituições federais de educação tecnológica, para fins de constituição dos Institutos Federais de Educação, Ciência e Tecnologia, no âmbito da Rede Federal de Educação Tecnológica. Brasília, 2007. Disponível em: <planalto.gov.br/ccivil_03/_ato20072010/2007/decreto/d6095.htm>. Acesso em: 8 out. 2013.

BRASIL. Chamada Pública MEC/SETEC no 002/2007. Chamada Pública de Propostas para constituição dos Institutos Federais de Educação, Ciência e Tecnologia. MEC/Brasília. 2007. Disponível em: <portal.mec.gov.br/arquivos/pdf/chamada_publica_IFs3.pdf>. Acesso em: 20 mar. 2014.

BRASIL. Lei no 11.892, de 29 de dezembro de 2008. Institui a Rede Federal de Educação Profissional, Científica e Tecnológica, cria os Institutos Federais de Educação, Ciência e Tecnologia, e dá outras providências. Brasília, 2008. Disponível em: <planalto.gov.br/ccivil_03/_Ato2007-2010/2008/Lei/L11892.htm>. Acesso em: 3 fev. 2013.

CAPES, MEC. Capes, 50 anos: Depoimentos ao CPDOC-FGC. Fundação Getúlio Vargas, CPDOC, 2002.

CAPES, Plano Nacional de Pós-Graduação, (considerações preliminares para o V PNPG), Comissão Mista CAPES/CNPq para o Desenvolvimento da Pós-Graduação e da Ciência e Tecnologia -Portaria Interministerial MCT/MEC número 270, 2004.

FISCHER, T. Mestrado profissional como prática acadêmica. RBPG - Revista Brasileira de PósGraduação, v. 2, n. 4, p. 24-29, jul. 2005.

FISCHER, T. M. D.; WAIANDT, C.; FONSECA, R. L. Educação Profissional e Pós-Graduação: um desafio estratégico para transformação do espaço educacional. Em: III Encontro de Ensino e Pesquisa em Administração e Contabilidade - EnEPQ, João Pessoa, 2011.

HOSTINS, R.C.L. Os Planos Nacionais de Pós-Graduação (PNPG) e suas repercussões na PósGraduação brasileira. PERSPECTIVA, Florianópolis, v. 24, n. 1, p. 133-160, jan/jun, 2006.

LAKATOS, E.; MARCONI, M. A. Fundamentos de metodologia científica. 5. ed. São Paulo: Atlas, 2003.

LIMA, F. B. G. de. A formação de professores nos Institutos Federais de Educação, Ciência e Tecnologia: um estudo da concepção política. Brasília: UnB, 2012.

MANFREDI. S. M. Educação Profissional no Brasil. São Paulo: Cortez, 2002. 
MARTINS, C. B. A CAPES e a formação do Sistema Nacional de Pós- Graduação. Em: FERREIRA, Marieta de Moraes; MOREIRA, Regina da Luz. CAPES, 50 anos: depoimentos ao CPDOC/FGV. Brasília: CAPES, p. 295-310, 2002.

MEC. Secretaria de Educação profissional e Tecnológica. Um novo modelo de educação profissional e tecnológica: concepção e diretrizes. Brasília: SETEC/MEC, 2010. Disponível em: <portal.mec.gov.br/index.php?option=com_content\&view=article\&id=12503\&ltemid=841>. Acesso em: 20 mar. 2014.

MEC. Secretaria de Educação profissional e Tecnológica. Concepções e diretrizes dos institutos federais de educação, ciência e tecnologia. Brasília: SET/MEC 2010. Disponível em: $<$ redefederal.mec.gov.br/index.php?option=com_content $\&$ view=article\&id=55\&ltemid=50>. Acesso em: 14 jan. 2013.

OTRANTO, C. R. Criação e Implantação dos Institutos Federais de Educação, Ciência e Tecnologia. Revista Retta. UFRRJ/PPGEA, Seropédica, RJ: EDUR, Vol. I, n. 1, p. 89-108, jan./jun. 2010.

PACHECO, E. (org.). Institutos Federais: uma revolução na educação profissional e tecnológica. Brasília: SETEC/MEC, 2010. Disponível em: <portal.mec.gov.br/index.php? option=com_content\&view=article\&id=12503\&ltemid=841>. Acesso em: 15 mar. 2014.

RIBEIRO, R. J. O mestrado profissional na política atual da CAPES. RBPG, Brasília, v. 2, n. 4, p. 8-15, jul. 2005. Seção Debates. Disponível em: $<$ www2.CAPES.gov.br/rbpg/portal/conteudo/Debates_Artigo1_n4.pdf>. Acesso em: 5 mar. 2008.

RIBEIRO, R. J. Mestrado profissional, mestrado acadêmico e doutorado. Disponível em: <CAPES.gov.br/images/stories/download/artigos/Artigo_30_08_07.pdf>. Acesso em: 15 out. 2008.

RICHARDSON, R. J. et al. Pesquisa social: métodos e técnicas. São Paulo: Atlas, 1999.

SANTOS, J. Educação profissional e práticas de avaliação. São Paulo: Editora SENAE, 2010.

SCHWARTZMAN, S. Um espaço para a Ciência. A Formação da Comunidade Científica no Brasil, Brasília: MCT/CGEE. 2001.

SILVA, Caetana Juracy (org.). Institutos Federais Lei 11.892, de 29/12/2008: comentários e reflexões. Natal: IFRN, 2009.

TRINDADE, H. 2002. Metáforas da crise e a urgência da reforma universitária na América Latina. Em: CARDIEL, H (org.). Nuevas Políticas de la Educación Superior. Série Universidad Contemporanea. A. Coruña, p. 129-160, 2002.

VERGARA, S. C. Métodos de pesquisa em administração. São Paulo: Atlas, 2005. 